\title{
Advances in the Molecular and Cellular Biology of Strongyloides spp.
}

\author{
Tegegn G. Jaleta ${ }^{1} \cdot$ James B. Lok ${ }^{1}$
}

Published online: 13 September 2019

(C) The Author(s) 2019

\begin{abstract}
Purpose of Review This paper constitutes an update of recent studies on the general biology, molecular genetics, and cellular biology of Strongyloides spp. and related parasitic nematodes.

Recent Findings Increasingly, human strongyloidiasis is considered the most neglected of neglected tropical diseases. Despite this, the last 5 years has seen remarkable advances in the molecular biology of Strongyloides spp. Genome sequences for S. stercoralis, S. ratti, S. venezuelensis, S. papillosus, and the related parasite Parastrongyloides trichosuri were created, annotated, and analyzed. These genomic resources, along with a practical transgenesis platform for Strongyloides spp., aided a major achievement, the advent of targeted mutagenesis via CRISPR/Cas9 in S. stercoralis and S. ratti. The genome sequences have also enabled significant molecular epidemiologic and phylogenetic findings on human strongyloidiasis, including the first genetic evidence of zoonotic transmission of S. stercoralis between dogs and humans. Studies of molecular signaling pathways identified the nuclear receptor Ss-DAF-12 as one that can be manipulated in the parasite by exogenous application of its steroid ligands. The chemotherapeutic implications of this were unscored by a study in which a $S s$-DAF-12 ligand suppressed autoinfection by $S$. stercoralis in a new murine model of human strongyloidiasis.

Summary Seminal advances in genomics of Strongyloides spp. have transformed research into strongyloidiasis, facilitating fundamental phylogenetic and epidemiologic studies and aiding the deployment of CRISPR/Cas9 gene disruption and editing as functional genomic tools in Strongyloides spp. Studies of Ss-DAF-12 signaling in S. stercoralis demonstrated the potential of this pathway as a novel chemotherapeutic target in parasitic nematodes.
\end{abstract}

Keywords Strongyloides $\cdot$ Genome $\cdot$ Transcriptome $\cdot$ Proteome $\cdot$ Transgenesis $\cdot$ CRISPR/Cas9

\section{Introduction}

Strongyloidiasis, caused mainly by Strongyloides stercoralis, is one of the most neglected soil-borne tropical diseases. Human infections with Strongyloides fuelleborni and S. fuelleborni kellyi have also been reported in Asia, Papua New Guinea, and some African locales [1-5]. Globally, S. stercoralis is reported to infect more than 370 million people mainly in tropical and subtropical regions [6]. However, this number may be a significant underestimate due to insensitive diagnostic techniques [6,7]. Strongyloidiasis is generally regarded as a problem in underdeveloped nations, but this

This article is part of the Topical Collection on Hot Topics in Tropical Medicine

James B. Lok

jlok@vet.upenn.edu

1 Department of Pathobiology, School of Veterinary Medicine, University of Pennsylvania, Philadelphia, PA, USA disease is also endemic in economically stressed and institutionalized populations in developed countries [7]. Travelers, tourists, military personnel, and immigrants from endemic regions can spread the parasite in developed countries [7]. S. stercoralis has a cosmopolitan distribution in tropical and subtropical regions of the world with the prevalence ranging from 5 to $40 \%$, with higher prevalence among young individuals and socioeconomically marginalized communities [7]. The high prevalence of S. stercoralis in tropical and subtropical regions is mainly attributed to high temperature, high moisture, poor sanitation, poor hygiene, and occupations such as farming and mining that increase the chance of individuals coming in contact with soils contaminated with infective third-stage larvae (iL3) of $S$. stercoralis [7]. In the USA, a series of small studies in selected populations have shown that between 0 and $6.1 \%$ of persons sampled were infected. However, studies of immigrant populations in the USA have revealed prevalence of infection as high as $49.2 \%[7,8]$.

$S$. stercoralis infections have also been described in dogs, cats, and several nonhuman primates [2, 9-12]. The 
prevalence of $S$. stercoralis in dogs ranges from 0 to over $45 \%$, with younger dogs and puppies more likely to be infected and to exhibit serious or fatal illness [2]. S. stercoralis iL3s in the external environment generally infect the host by skin penetration (percutaneous route) [1], but in addition, transmammary transmission has been observed in lactating bitches $[13,14]$. The transmammary route of transmission of S. stercoralis has not been reported in humans thus far. Natural infections of dogs with a human strain of $S$. stercoralis have been reported in rural communities in Southeast Asia [15••, $16,17]$. Hence, the zoonotic importance and the potential of dogs as a reservoir of $S$. stercoralis to humans are receiving attention in the scientific community [15••, 17].

In immunocompetent and healthy individuals, S. stercoralis causes chronic asymptomatic infections with few or no symptoms or lesions [18]. Symptomatic individuals with chronic strongyloidiasis may present with gastrointestinal indicators such as diarrhea, constipation, and intermittent vomiting [19]. Cutaneous lesions such as urticaria and rashes are also common in symptomatic chronic strongyloidiasis [19]. However, in immunocompromised patients, strongyloidiasis can cause severe generalized and complicated fatal systemic infections from exponential multiplication and dissemination of autoinfective S. stercoralis third-stage larvae (aL3) which involve gastrointestinal, respiratory, central nervous systems [20, 21]. Hyperinfection syndrome occurs when aL3 penetrate the small intestinal mucosa in large numbers and migrate somatically, resulting in severe systemic symptoms and organ failure [22]. Hyperinfection syndrome is commonly reported in individuals under corticosteroid treatment and cases of human Tlymphotropic virus type 1 (HTLV-1) co-infection with S. stercoralis $[21,23]$. Complicated strongyloidiasis due to hyperinfection and dissemination of autoinfective larvae into vital organs such as liver, lung, and brain can result in death in $85 \%$ of the cases [24] unless anti-Strongyloides chemotherapy is given in time [25, 26]. Migrating autoinfective larvae also disseminate enteric microorganisms to these organs, which requires administration of broad spectrum antibiotics to prevent fatal septic shock and meningitis [27].

A previous review in Current Tropical Medicine Reports [28] covered contemporary advances in the cellular and molecular biology of Strongyloides spp. up to 2014. The present review is intended to provide updates in the general areas covered in that review.

\section{Basic Biology}

\section{Life Cycle}

Strongyloides spp. have unique and complex life cycles that alternate between parasitic and free-living generations [29]. The host is infected when iL3 penetrate the host skin, migrate through the host body, and finally establish themselves in the mucosa of small intestine. During this process, the iL 3 molt twice to develop to parasitic adult females. From more than 50 species of the genus Strongyloides described, there is not a single report of parasitic males. The adult parasitic female spends its life embedded in the mucosa of the small intestine mainly in the duodenal region. The parasitic female produces eggs by mitotic parthenogenesis (asexual reproduction). $S$. stercoralis eggs hatch in the small intestine and male and female first-stage larvae (L1) pass to the environment with the host feces. A proportion of female L1 in the extrinsic environment develops via a homogonic cycle directly to iL3, which must infect a susceptible host in order to develop further. The remainder of the L1s develops via a heterogonic cycle to freeliving males and females, undergoing four molts in the process. Free-living adults reproduce sexually to produce only female progeny that develop to iL3 that require a host for further development [30, 31]. Free-living development by most Strongyloides spp. is limited to a single generation, but Strongyloides planiceps, a parasite of cats, can undergo up to nine sequential generations of free-living development, but with decreasing brood sizes in each [32]. iL3 of $S$. stercoralis can live in the environment (soil) for about 2 weeks until they encounter a suitable host, where they penetrate the host skin to initiate the parasitic life cycle. As discussed above, $S$. stercoralis also has the unique ability to execute autoinfection when female L1 develop precociously to autoinfective aL3 in the intestine instead of passing with the host feces as L1. These aL3 penetrate the intestinal wall or the perianal skin to continue re-infecting the same host through repeated generations. In immunocompetent patients, wellregulated autoinfective cycling of $S$. stercoralis can maintain chronic subclinical infection for decades without further input if iL3 from the environment [33]. By contrast, in immunocompromised individuals, the autoinfective cycle proceeds in unregulated fashion and can result in hyperinfection syndrome with geometric increases in parasite burden, which may result in fatal illness from dissemination of autoinfective larvae and pathogenic gut microbes. Due to its unique and complicated life cycle, S. stercoralis poses a serious risk to public health in both endemic and nonendemic regions, unless appropriate health and environmental management strategies are properly and effectively implemented.

\section{Germline Organization, Reproduction, and Sex Determination}

The model nematode, Caenorhabditis elegans, has a tubular gonad in both sexes [34]. In hermaphrodites, the gonad has two arms, one extending posteriorly and the other anteriorly with both arms ending at vulva. In males, the gonad has only one arm with a caudal opening. The distal tip cell sits at the terminus of each gonadal arm and signals the nearby germ 
cells to proliferate mitotically [35]. Germ cells exit the mitotic cycle when they move away from the distal cell signal. At this point, they initiate meiosis and begin to differentiate into gametes. Most nematodes, including C. elegans and Pristionchus pacificus, maintain their stem cell populations at the distal end of each gonadal arm ensuring a constant flow of differentiated germ cells [36]. The gonad of the C. elegans hermaphrodite is packed with mitotically dividing germ cells, crescent-shaped nuclei at the transition zone, "bowl of spaghetti" nuclei in the pachytene zone, and condensed chromosomes at diakinesis [37•]. By contrast, proliferating germline stem cells are absent in adult Strongyloididae. In female Strongyloides ratti, the entire distal arm is filled with giant nuclei, followed by a band of compact small nuclei at the gonadal loop. The germline organization in male $S$. ratti is basically similar to the female one except strongly condensed small nuclei at the end of the gonad [37•]. Staining based on histone modification showed similar staining patterns in male and female $S$. papillosus, $S$. ratti, and Parastrongyloides trichosuri (P. trichosuri) [37•]. Parasitic female $S$. ratti and S. papillosus and freeliving males showed strikingly similar patterns staining with $\mathrm{H} 3 \mathrm{~K} 4 \mathrm{me} 3$ and H3Pser10 regardless of the absence of meiosis in parasitic females [37•]. The distal gonads of free-living female and male $S$. ratti and $S$. stercoralis have syncytial zones that may be used as microinjection sites for recombinant DNA to generate transgenic parasites [38 $8^{\bullet}$.

Most Strongyloides spp. and P. trichosuri follow XX/XO sex determination mechanisms suggesting that $\mathrm{XX} / \mathrm{XO}$ sex determination is ancestral in the family Strongyloididae [39]. In Strongyloides spp., meiotic recombination only occurs in the free-living generations because females of the parasitic generation reproduce by mitotic parthenogenesis [29]. Due to the presence of an extra $\mathrm{X}$ chromosome, parasitic females are capable of producing male and female offspring parthenogenetically. The molecular, cellular, and genetic mechanisms that control parthenogenesis in Strongyloides spp. are poorly understood. In S. ratti and S. stercoralis, both sexes have two pairs of autosomes, and the females have two $\mathrm{X}$ chromosomes $(2 n=6)$ but the males have only one $(2 n=5)$ [40]. Linkage mapping in $S$. ratti showed the presence of recombination in all three of its chromosome pairs, with a much lower frequency of these events in X chromosomes [41].

In S. papillosus and S. vituli, fusion of chromosome I and the $\mathrm{X}$ chromosome result in formation of a hemizygous region [42]. Females carry two pairs of a large (L) and a medium (M) $(2 n=4)$ chromosomes. Males undergo sex-specific chromatin diminution where the middle of one $\mathrm{L}$ chromosome is removed by programmed DNA elimination to form two fragments, which are retained as separate chromosomes, with the result that $2 n=5$ chromosomes [29]. The region undergoing chromatin diminution is surrounded by noneliminated chromatin and two breakpoints that occur between the eliminated and noneliminated region of one of the large chromosome
[29]. Comparative miRNA analyses of different developmental stages of $S$. ratti and $S$. papillosus revealed similar results suggesting that miRNA has no role in sex-specific chromatin diminution in S. papillosus [43]. We know very little about how chromatin diminution happens and its mechanism of inheritance in Strongyloides spp. In S. papillosus, males transfer the intact large chromosome but not the diminished chromosome to their offspring. However, the females randomly pick and pass one of the two large chromosomes [42]. Genetic recombination in $S$. papillosus $(2 n=4)$ occurs only in nondiminished chromosomes in both sexes [42]. The diminished regions of the S. papillosus chromosome are homologous to the X chromosome in $S$. ratti [42, 44]. We know little about the discrepant patterns of the inheritance of the sex chromosomes in these two species. The diminished region in the $S$. papillosus chromosome carries a large number of genes with known biological functions in C. elegans [42]. In addition to chromosomal differences, environmental factors such as the host immune status also affect sex determination in Strongyloides spp. In the case of $S$. ratti, a strong immune response against it in the rodent host results in a higher proportion of males in the fecal culture [45].

\section{Host Specificity, Genetic Diversity, and Zoonoses}

The genus Strongyloides contains about 50 species which are all obligate gastrointestinal parasites of various vertebrates including humans, birds, amphibians, reptiles, and several mammals [13]. Strongyloides species are generally host-specific, but the medically important human parasites, S. stercoralis and S. fuelleborni, are known to have broad host range $[3,15 \bullet \bullet, 46]$. Natural $S$. stercoralis infections have been identified in humans, dogs, cats, and several nonhuman primates [8-11, 18, 21, 47-49]. Recently, molecular and genetic studies in S. stercoralis isolated from different hosts and locations revealed the presence of huge genetic variations between these isolates. Jaleta et al. [15••] isolated $S$. stercoralis from humans and dogs in the same household in rural Cambodia and conducted single worm molecular genotyping using the nuclear 18S rDNA hypervariable region (HVR) I, HVR-IV, the mitochondrial coxl gene and single worm whole genome sequencing. HVR-I is generally used to detect polymorphisms within the same species Strongyloides spp., whereas HVR-IV is invariable within the same species and therefore usually used for species identification. The maternally inherited mitochondrial coxl gene is generally used to identify distinct haplotypes and cryptic species in Strongyloides molecular taxonomy. Genotyping of more than 500 single worms using HVRI as a marker revealed more than 5 genotypes with T/A substitutions at position 458 and a stretch of $5 \mathrm{~T} / 4 \mathrm{~T}$ consisting of a single base indel at position 176-179. A genotyping scheme using HVR-IV revealed two genetically distinct populations of $S$. stercoralis in these two hosts. One population occurred 
only in dogs, while the other population was present in dogs and humans. The phylogenetic relationships inferred using both nuclear 18S rDNA HVR-IV and mitochondrial coxl sequences were basically similar suggesting strong separation of human-dog and dog-specific strains of $S$. stercoralis. Nagayasu et al. [17] also reported the existence of two genetically distinct lineages and clades of $S$. stercoralis isolated from dogs and humans in Japan and Myanmar using a genotyping scheme similar to that of Jaleta et al. [15••]. Several $S$. stercoralis larvae with different HVR-I and IV genotypes were identified from the same dogs, and there was no evidence of crossing among larvae with different genotypes $\left[15 \bullet^{\circ}\right]$. These results provided the first direct evidence of zoonotic and canine-specific populations of $S$. stercoralis, which would constitute cryptic species of $S$. stercoralis present only in domestic dogs and not in humans [15••, 16, 17].

S. fuelleborni infections have also been widely reported in humans and several nonhuman primates such as chimpanzees, gorillas, macaques, and baboons [3-5, 12]. However, due to the absence of autoinfection in S. fuelleborni infections, the disease associated with them in humans is not as severe as in $S$. stercoralis infections [46]. The single worm genotyping scheme for $S$. stercoralis described above has also been widely applied to $S$. fuelleborni isolated from humans, nonhuman primate hosts, and different geographic locations. These studies revealed large genetic variations and several distinct clades of S. fuelleborni depending on the host and geographic locations where the parasites were collected [4, 5]. HVR-IV and coxl genotyping of Strongyloides spp. isolated from stools of humans, gorillas, and chimpanzees in Central African Republic and Uganda identified several distinct sequence types of S. fuelleborni [4]. Distinct haplotypes of S. fuelleborni from humans and long-tailed macaques in Thailand and Laos were also described and phylogenetically characterized using partial coxl sequences [5]. Three distinct clades of S. fuelleborni and other cryptic Strongyloides spp., which were close to $S$. stercoralis isolated from primates, were also discovered in Malaysia using partial coxl sequence genotyping [3].

S. stercoralis and S. fuelleborni are the two species of Strongyloides with zoonotic potential and so pose a serious public health risk in endemic areas. The presence of broad genetic diversity in $S$. stercoralis and $S$. fuelleborni indicates a complex genetic mechanism by which these parasites adapted to human, nonhuman primate, and canine hosts and to diverse geographic locations. To minimize the public health risks of S. stercoralis and S. fuelleborni, strongyloidiasis control and prevention strategies should include regular mass anthelmintic treatment of dogs and captive and semidomestic primates. However, to design and formulate strong and effective control and prevention strategies, several comprehensive and large-scale comparative genotyping and population genetic studies should be conducted in potential reservoir hosts and geographical regions in endemic areas. Recent molecular genetic studies focusing on the zoonotic potential of S. stercoralis and S. fuelleborni isolated from humans, dogs, cats, and nonhuman primates are presented in Table 1.

S. papillosus is generally known to parasitize sheep and several other domestic and wild ruminants [13]. However, Eberhardt et al. [52] found $S$. vituli, which differs genetically from S. papillosus, to be the predominant member of the genus-infecting cattle. It could be possible that most domestic and wild ruminants are infected with genetically diverse S. papillosus and other distinct Strongyloides spp. S. papillosus can cause fatal illness in lambs, kids, and calves kept under intensive management. Regardless of its significant veterinary importance, there are very few studies reported to describe the genetic diversities and population genetics of this group of animal parasites.

\section{Physicochemical Communication Between S. stercoralis and Its Host}

Strongyloides spp. infect their mammalian hosts by active penetration of skin in a manner similar to the percutaneous route of infection by larval hookworms [31]. Infective iL3 develop in the soil either directly from L1 voided in the feces or indirectly via a generation of free-living males and females. Castelletto et al. [53] aptly characterized iL3 of Strongyloides spp. as fast migrating "cruisers" that disperse away from feces, close upon a stationary host and exhibit stereotypic behaviors such as nictation that enhance the likelihood contacting it. Recent reviews $[54,55]$ effectively capsulize findings to date on mediation of host seeking behaviors by physical and chemical cues emanating from the host. Briefly, host seeking by environmental iL3 of parasitic nematodes comprises orientation along gradients of heat and both volatile and soluble chemicals from the host. Within physiological limits, S. stercoralis migrates up a temperature gradient approximating the transition from the environment to the host skin and body temperatures. However, temperatures experienced by S. stercoralis iL3 in the hours leading up to a host encounter may significantly affect the proportion of larvae that migrate up the gradient $\left[54,56^{\circ}\right]$ with lower environmental temperatures increasing the likelihood of iL3 migrating toward host body temperature. Temperature may also determine responsiveness of $S$. stercoralis larvae to chemoattractants [57].

Soluble attractants include components of sweat such as sodium chloride, serum factors, and a mammalian skin constituent, urocanic acid [55, 58-60]. Among potential volatile mediators, $\mathrm{CO}_{2}$ repels $S$. stercoralis iL3 at high concentrations and is neutral at lower ones. Intriguingly, almost all of the host-emitted volatile compounds from a large panel S. stercoralis iL3 attractants also attract mosquitoes to mammalian hosts $[53,55]$. 


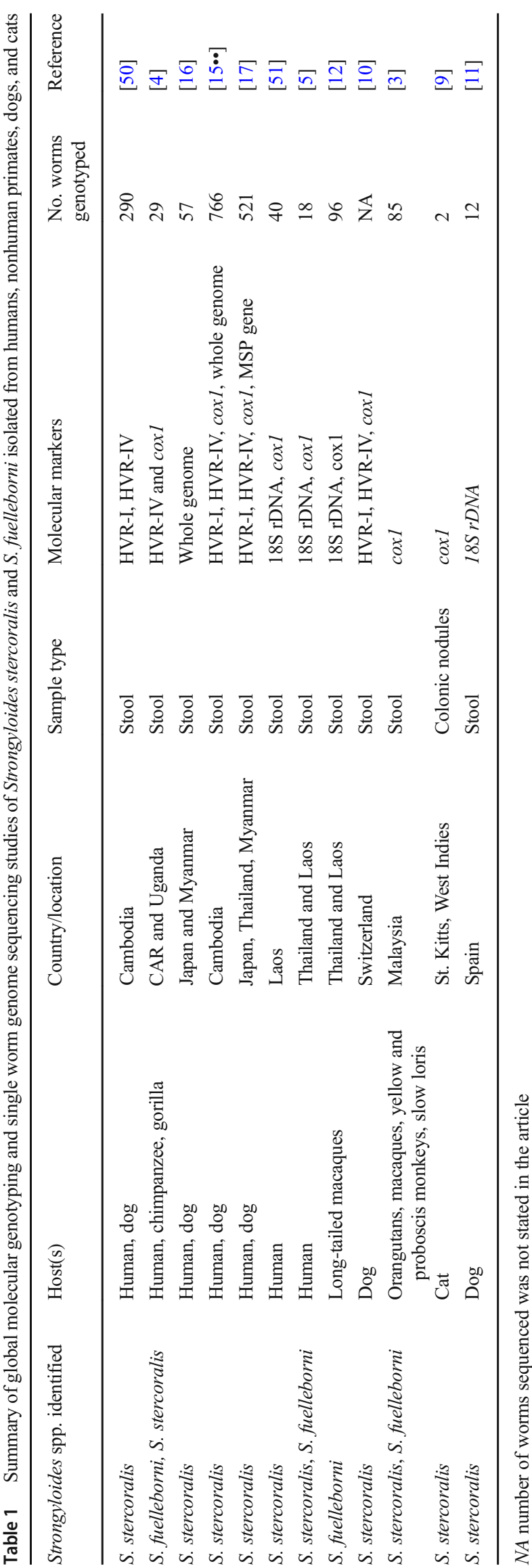

The most significant recent advancement in studies of host seeking and other chemically mediated behaviors in soiltransmitted nematodes is marked by the advent of targeted mutagenesis by CRISPR/Cas9 in Strongyloides spp. [61••, 62] and its application to discerning function in molecular components of sensory neuronal signaling. CRISPR/Cas9 knockout (discussed in detail below) of Ss-TAX-4, which encodes one of two subunits of a cGMP-gated ion channel in sensory neurons, demonstrated that this gene is required for normal thermotaxis by $S$. stercoralis iL3 [54, 56॰]. Given that TAX-4 is highly conserved in sensory neurons of nematodes, it will be interesting to see whether knockouts of this gene also affect chemotaxes as well.

Once $S$. stercoralis iL3 have penetrated the host skin, they must initiate a lengthy somatic migration that ultimately takes them to the lung and then to the small intestine. The calcium binding protein venestatin, recently discovered in the hypodermis and intestinal epithelium of S. venezuelensis iL3 and in their excretory secretory products, appears to be required for migration of these infective larvae from the skin to the lungs of experimentally infected mice [63]. Immunization of mice against venestatin reduces burdens of larvae in the lungs and intestine on days 2 and 3 of a challenge infection with S. venezuelensis iL3 [63], at once indicating the requirement for this protein in normal migration of the parasite in its host and the potential of venestatin as a vaccine target against Strongyloides spp. and possibly other soil-transmitted helminths.

\section{Animal and In Vitro Models for the Study of Human Strongyloidiasis}

Animal and in vitro models are essential for maintaining Strongyloides spp. in the laboratory and for experimentation to elucidate basic molecular mechanisms involved in the infectious process and to discover new drug and vaccine targets in these parasites. The Mongolian gerbil constituted the first small animal model of both uncomplicated and hyperinfective S. stercoralis infection [64]. Initial work by Nolan and colleagues [64] on the gerbil model involved an S. stercoralis strain of canine origin. A notable recent development is the experimental infection of gerbils with a human isolate of S. stercoralis [65]. This achievement underscores the utility of the gerbil model as a tool for long-term maintenance of field isolates of $S$. stercoralis and its applicability to the study of zoonotic transmission of this parasite between humans and dogs. The power of the gerbil model lies in the susceptibility of this rodent species to infection with $S$. stercoralis and the fidelity with which it recapitulates the infective and autoinfective cycles of this parasite. While the gerbil model is invaluable for parasitological study of Strongyloides spp., the lack of highly inbred strains and of the ability to engineer its genome and the paucity of antibody and cytokine reagents 
limit the gerbil's value as a subject for immunological study compared to murine models of parasitic nematode infection. Previous attempts to establish patent infection with $S$. stercoralis in immunocompromised mice have met with limited success, so the recent discovery that the NOD/LtSzscid IL2R $\gamma^{\text {null }}$ (NSG) mouse can support both uncomplicated and hyperinfective $S$. stercoralis infection is highly significant [66••]. The capacity to engraft the NSG mouse with cytokinemobilized stem cells that give rise to multiple components of the human immune system [67] opens broad avenues for in vivo research in human immunology and in immunoparasitology. However, neither the gerbil nor the mouse is a natural host of any Strongyloides species, and generally, inocula exceeding $100 \mathrm{iL} 3$ are required to establish a patent infection with $S$. stercoralis in these animals. While this level of susceptibility is sufficient for routine strain maintenance, it represents a significant hurdle to establishing stable lines of genetically defined or transgenic $S$. stercoralis, where numbers of founding iL3 are frequently limited to 10 or 20 $[61 \bullet \bullet, 68]$. One remedy for this problem has been to utilize species of Strongyloides that naturally parasitize rats, $S$. ratti and $S$. venezuelensis, as subjects for the establishment of such lines. In their excellent review [69], Viney and Kikuchi discuss many aspects of the biology of these rat parasites with particular emphasis on their utility in investigations of host immunity and its effects on parasite biology and in the derivation of genetically defined parasite lines. In the case of $S$. ratti, the fact of a well-adapted pairing of parasite and rat host allows for the establishment of patent infections with a single inoculated iL3 in most attempts. This property has allowed the establishment of stable transgenic lines of $S$. ratti [38], and it promises to facilitate establishment of lines carrying mutations induced by CRISPR/Cas9 [61••]. It is noteworthy that once stabilized in rats, lines of transgenic $S$. ratti can be maintained for several months in gerbils (Lok et al., unpublished).

Advances in in vitro culture technique for both parasites and host tissues will also enhance laboratory models for the study of strongyloidiasis. Agar plate culture is essential for phenotyping the free-living stages of parasitic nematodes. Initial approaches to agar plate culture have involved direct application of conditions originally derived for the free-living nematode $C$. elegans. These comprise plates containing nematode growth medium (NGM) agar with lawns of the OP50 strain of Escherichia coli bacteria [70]. While this system supports survival of Strongyloides spp. including $S$. stercoralis and $S$. ratti, the fecundity and longevity of the free-living stages of Strongyloides spp. reared on such plates is significantly compromised. In response, Dulovic and coworkers [71] undertook a systematic effort to optimize agar plate culture conditions for $S$. ratti and arrived at a combination of V12 agar with a lawn of the HB101 strain of $E$. coli that optimizes brood size, egg hatchability, and adult longevity in cultured free-living stages of this parasite. This and similar advances in culture technique for $S$. ratti and other Strongyloides spp. stand to facilitate derivation of transgenic and other genetically defined lines of these parasites, which has been hampered in the past by suboptimal culture systems.

The first encounter between Strongyloides spp. and their mammalian hosts involves contact and penetration of host skin by iL3. Studies deploying in vitro models of skin penetration by iL3 of Strongyloides spp. and hookworms such as Ancylostoma spp., which may also invade the host percutaneously, have revealed that this event may trigger early events comprising reactivation of these developmentally quiescent infective larvae [72, 73]. These model systems generally involve a glass apparatus, dubbed a PERL chamber that comprises upper and lower compartments filled with a physiological medium, the lower compartment being warmed to host body temperature, and separated by a layer of mammalian skin recovered from some laboratory animal at necropsy. Percutaneous migration of iL3 in such an apparatus stimulates early markers of reactivation such as resumption of feeding in the hookworm Ancylostoma caninum [73] and upregulation of an aspartic protease (and vaccine candidate) encoded by Spa-asp-2 in S. papillosus [72]. Skin samples used in such PERL chambers can constitute a source of technical variation due to their species of origin, thickness, inclusion of subcutaneous fat, storage parameters (frozen or fresh), and other factors that are difficult to control. In view of this, the achievement of an engineered three-dimensional skin equivalent culture, derived entirely from continuous lines of component cells [74], represents a very significant advancement in the study of percutaneously invasive larvae of parasitic helminths. In this instance, $S$. ratti iL3 were unable to penetrate the full-thickness skin equivalent structures but could traverse a cell-free collagen scaffold. By contrast, cercariae of Schistosoma mansoni could penetrate the full-thickness skin equivalents. Therefore, while technical modifications are required before this system can be deployed for studies of parasitic nematodes, engineered full-thickness skin equivalents seem poised to obviate the need for skin explants from euthanized animals and to eliminate the confounding variance inherent in using skin samples from a variety of sources and subjected to nonstandardized storage conditions.

\section{Manipulation of Cellular Signaling Pathways in the Infective and Autoinfective Processes}

For over two decades, the morphological, behavioral, and molecular genetic aspects of dauer larval development in C. elegans have been regarded as a paradigm for framing hypothesis about the molecular signaling mechanisms that govern the development of iL3 of parasitic nematodes before, during, and after the infective process [75]. Published findings support that the canonical dauer regulatory signaling pathways in $C$. elegans, $\mathrm{G}$ protein-coupled sensory signaling, 
insulin-like signaling and steroid-nuclear receptor (NR) signaling involving homologs of the DAF-12 NR, and its dafachronic acid ligands are conserved in several soiltransmitted parasitic nematode species, including Strongyloides spp., and operate in sequence to regulate developmental arrest of iL3 in the environment and their reactivation following host infection [76]. The DAF-12 NR is conserved in S. stercoralis and Ancylostoma caninum, and developing larvae of these parasites respond to exogenous dafachronic acids in a manner consistent with dauer hypothesis [77]. That is, exogenous dafachronic acid stimulates resumption of feeding by iL3 of Ancylostoma caninum and S. stercoralis [77-79], just as it promotes the analogous process of dauer recovery in C. elegans [80]. Conversely, when applied to developing larval progeny of free-living $S$. stercoralis and $S$. ratti adults, dafachronic acid suppresses morphogenesis and developmental arrest of iL 3 and promotes formation of second-generation rhabditiform fourth-stage larvae and reproductive adults, respectively [77, 78, 81]. Similarly, exogenous dafachronic acid can promote switching from the parasitic to the free-living developmental alternative in first-stage larval progeny of parasitic female $S$. stercoralis [78]. The studies mentioned above stressed phenotypic observations of parasitic nematode larvae following treatment with exogenous dafachronic acid and so left open the question of whether endogenous production of dafachronic acid ligands of known DAF-12 homologs occurs within the worms. Given that the final step in biosynthesis of dafachronic acids from dietary cholesterol in C. elegans is catalyzed by the DAF-9 cytochrome P450 (CYP), this question was addressed by assessing phenotypes resulting from blocking overall CYP function in S. stercoralis with the inhibitor ketoconazole. Ketoconazole treatment resulted in a dose-dependent suppression of resumed feeding by $S$. stercoralis iL3 under host-like culture conditions, and this phenotype could be rescued by exogenous $\Delta 7$-dafachronic acid, providing indirect evidence that endogenous dafachronic acid synthesis is required for this crucial event in the infectious process and indicating the potential of CYP function as a chemotherapeutic target in S. stercoralis and other soil-transmitted parasitic nematodes [78]. Further studies of DAF-12 signaling in nematodes revealed that in both C. elegans and S. stercoralis, this pathway also regulates genes involved in the aerobic catabolism of fatty acids, a process that supports reproductive growth of adult stages, both parasitic and free-living [82].

The ability of dafachronic acid to suppress the formation of iL3 in the post free-living generation of $S$. stercoralis $[77,78]$ prompted a hypothesis that when administered orally, this steroid might also prevent the formation of aL3 of this parasite within the guts of infected hosts and thereby prevent disseminated hyperinfection that causes the most serious complication of human strongyloidiasis. This hypothesis was supported by observations that $10 \mu \mathrm{M} \Delta 7$-dafachronic acid can suppress populations of $S$. stercoralis aL3 when administered in drinking water to infected NSG mice treated with methylprednisolone acetate to incite autoinfection [66••]. This finding is significant in that it constitutes evidence that DAF-12 signaling regulates the formation of aL3 in S. stercoralis and that this event requires downregulation of the DAF-12 ligand. This, along with the previous finding that the cytochrome $\mathrm{P} 450$ inhibitor ketoconazole suppresses developmental activation of $S$. stercoralis iL3 in a manner that can be partially reversed by $\Delta 7$-dafachronic acid, demonstrates how $S s$-DAF-12 signaling can be manipulated by administered small molecules to either block the initial infective process (by ketoconazole or other cytochrome P450 inhibitor, Fig. 1a) or to suppress autoinfection (by $\Delta 7$ dafachronic acid or analog, Fig. 1b). This factor argues strongly for efforts to develop new chemotherapeutic agents targeting Ss-DAF-12 signaling to prevent infection, or, more practically, to suppress autoinfection in cases of in infected individuals. The latter intervention would serve to treat or prevent disseminated hyperinfection, the most serious, and potentially fatal, complication of human strongyloidiasis. Further discussion of the chemotherapeutic implications of this finding is discussed in a contemporaneous commentary [84].

S. stercoralis has also been used as a model in several recent studies of a family of RIO kinases that appear to be essential for normal development in this parasitic nematode and perhaps others [85-87]. RIO kinases constitute a family of atypical protein kinases that are named for the right open reading frame 1 domain that is a feature of the prototype for this family [85]. Of the three RIO kinases investigated in parasitic nematodes to date, RIOK-1 and RIOK-2 are conserved in taxa ranging from Archaea to humans [85, 87], while RIOK-3 is found only in multicellular eukaryotes [86]. RIOK-1 and RIOK-2 are both nonribosomal factors that are necessary for ribosomal biogenesis and normal cell cycle progression $[85,87]$. The cellular function of RIOK-3 is less well understood but appears to diverge from those of RIOK-1 and RIOK-2. RIOK-3 is associated with 40s ribosomal particles, but an explicit function for it in ribosome biogenesis has not been demonstrated [86]. RIOK-3 is upregulated in cancer cells where it modulates NF-KB signaling and so is likely required for tumor growth [86].

Consistent with a function in ribosomal biogenesis in S. stercoralis, Ss-RIOK-1 is expressed in the cytoplasms of hypodermal cells and of neurons throughout the head, body, and tail of developing larval progeny of free-living adults. Phenotypes resulting from expression of a kinase-dead mutant Ss-RIOK-1 in post free-living larvae support that catalytic function of this protein kinase is required for normal motility and development of larval S. stercoralis, and indicate its potential as a chemotherapeutic target [87]. To our knowledge, developmental patterns of Ss-riok-1 transcription have not been determined. $S s$-RIOK-2-specific transcripts are most abundant in parasitic females and in larval stages adult 

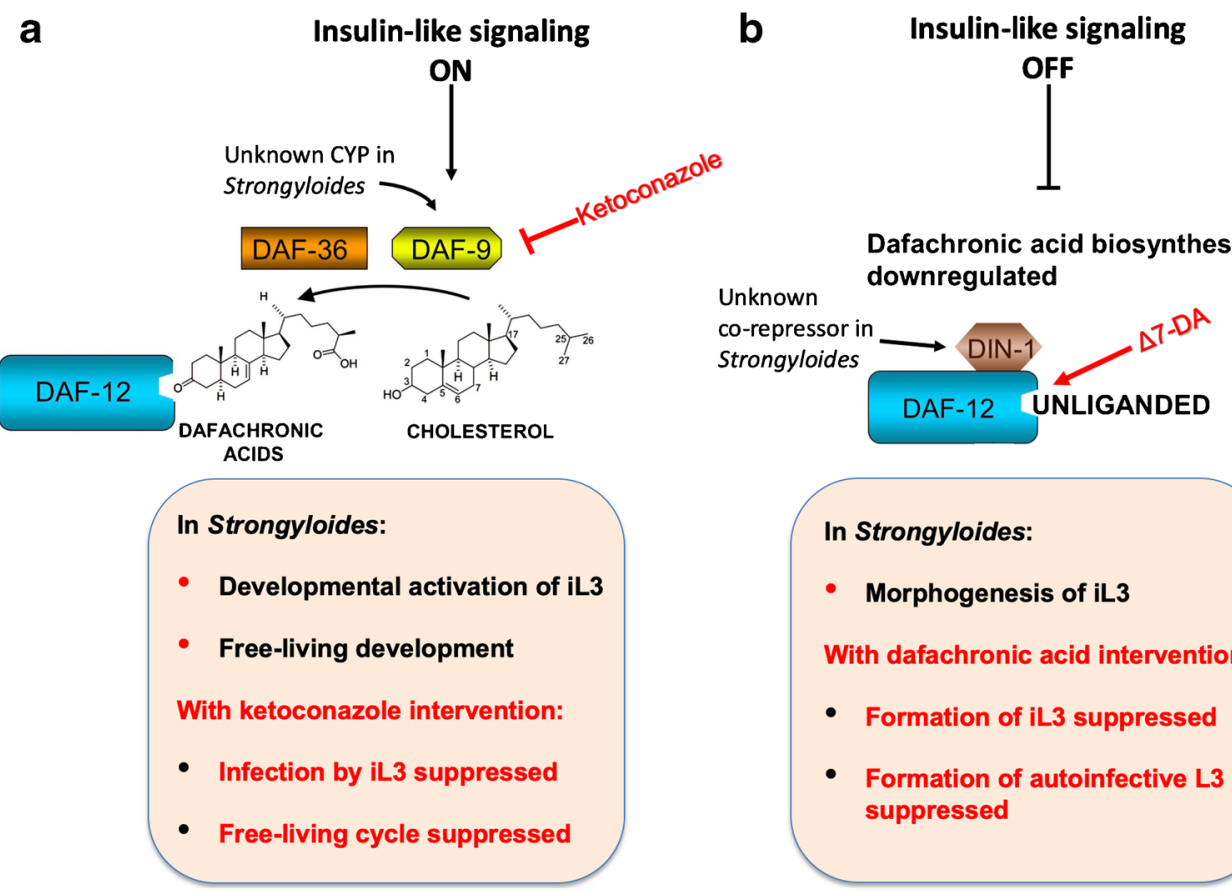

Fig. 1 Administered small molecules can manipulate $S s$-DAF-12 signaling to suppress infection and autoinfection by $S$. stercoralis. a Under natural conditions in nematode development, insulin-like signaling, along with TGF $\beta$-like signaling, upregulates biosynthesis of dafachronic acids from dietary cholesterol. In C. elegans, the DAF-9 cytochrome P450 (CYP) catalyzes the final oxidative step in this biosynthetic pathway [80, 83]. DAF-12 signaling is conserved in parasitic nematodes, including $S$. stercoralis [77], and previous findings indicate that the cytochrome P450 inhibitor ketoconazole can block developmental activation of infective third-stage larvae (iL3) of $S$. stercoralis under host-like culture conditions and that this effect is partially reversed by the DAF-12 ligand $\Delta 7$-dafachronic acid [78]. This finding underscores the potential of CYP function in DAF-12 signaling as

females of the free-living generation. They are downregulated significantly in post free-living larvae and iL3 but are then significantly upregulated in host-activated iL3, dubbed L3+ [85]. In contrast to $S s$-RIOK-1, Ss-RIOK-2 is expressed in the intestinal epithelium of post free-living larvae [85]. The divergent function of Ss-RIOK-3 compared to other members of the RIO kinase family is echoed by unique temporal and anatomical expression patterns in larval and adult S. stercoralis. Trends in abundance of Ss-RIOK-3-specific transcripts are like those of $S s$-RIOK2 only in that they peak in parasitic females. Beyond that, Ss-RIOK-3-specific transcript levels are similar in post parasitic and post free-living larval stages with a slight decline in post free-living L1 [86]. Anatomical patterns of Ss-RIOK-3 expression shift from a one favoring expression in intestine and head neurons in post freeliving L1 and L2 to one in which expression is limited to body wall muscle in post free-living iL3. Studies of RIO kinases in $S$. stercoralis drew upon the transgenesis platform that is available for this parasite. Details of this approach are discussed below in sections on manipulation of the genome and of gene expression in Strongyloides spp.

a chemotherapeutic target in blocking the infectious process by S. stercoralis. b Shutdown of insulin- and TGF $\beta$-like signaling in C. elegans downregulates dafachronic acid biosynthesis, and in its unliganded state, DAF-12 downregulates dauer formation and upregulates continuous development [80, 83]. Likewise, in Strongyloides spp., administration of $\Delta 7$-dafachronic acid suppresses iL3 morphogenesis and promotes formation of second-generation freeliving larvae and adults $[77,81]$. Significantly, administering $\Delta 7$ dafachronic acid orally to NSG mice undergoing autoinfection with S. stercoralis also suppresses morphogenesis of autoinfective L3 [66••], underscoring the potential of Ss-DAF-12 signaling as a chemotherapeutic target in potentially fatal disseminated hyperinfection in human strongyloidiasis [84]

\section{The Genomes and Transcriptomes of Strongyloides spp.}

With rapidly improving genomic and transcriptomic sequencing technologies, more efforts are being focused on assembly and complete annotation of the genomes of Strongyloides spp. of medical and veterinary importance to identify functional characterization of genes involved in development and parasitism. High-quality draft genome assemblies ranging from 42 to $60 \mathrm{Mb}$ are currently available for $S$. ratti $(43.1 \mathrm{Mb})$, S. stercoralis $(42.6 \mathrm{Mb}), S$. venezuelensis $(52.1 \mathrm{Mb})$, and S. papillosus $(60.2 \mathrm{Mb})[88 \bullet \cdot$. Strongyloides genomes are small compared to the genomes of C. elegans $(100 \mathrm{Mb})[89]$ and P. pacificus (169 Mb) [90]. Notably, S. ratti has the second most completely assembled and well-annotated nematode genome after that of $C$. elegans, with a high-quality $43 \mathrm{Mb}$ reference genome comprising two autosomes and an X chromosome [88••]. The S. papillosus genome is assembled into approximately 4000 scaffolds making it the least well assembled and annotated of the Strongyloides spp. genomes. This is due to the level of chromatin diminution in S. papillosus, which 
hampers genome assembly and annotation [88••]. In the future, more effort should be devoted to improving the assembly and annotation of the genome of this important ruminant parasite. The $S$. ratti and $S$. stercoralis genomes have GC contents of only 21 and $22 \%$, respectively, making them the most AT-rich nematode genomes reported to date $[88 \bullet \bullet$. The total proteincoding contents of the $S$. ratti and $S$. stercoralis genomes range between 18 and $22 \mathrm{Mb}$, and the predicted numbers of genes for S. ratti, S stercoralis, S. papillosus, and $S$. venezuelensis are $12,451,13,098,18,457$, and 16,904 , respectively [88••].

Transcriptomic information about the gene expression profiles of different developmental stages have been reported for S. ratti, S. stercoralis, S. venezuelensis, and S. papillosus [44, $88 \bullet \bullet, 91]$. In most of the comparative transcriptomic studies conducted to date, transcripts from astacin-like metalloproteinase, cysteine-rich secretory protein, antigen 5, and pathogenesis-related 1 protein $(\mathrm{CAP})$ gene families were the most significantly upregulated in parasitic adult and iL3 stages $[44,88 \bullet \bullet, 91]$. Notably, CAP and astacin gene families have undergone significant duplication and expansion in Strongyloides spp. [88••]. Apart from CAP and astacin gene families, genes encoding acetylcholinesterase, pyrolyl oligopeptidases, aspartic proteases, trypsin inhibitors, and transthyretin-like molecules are also greatly expanded, and their transcripts are highly abundant in parasitic adults and iL3 [44, 88••, 91, 92]. Products of these genes have been proposed as immunomodulatory molecules in parasitic nematodes [88••, 93], and their upregulation may be associated with infection of novel hosts, which makes members of these families primary candidates for genes associated with parasitism $[30,44,88 \bullet \bullet, 91]$. Hence, the biological functions of these proposed parasitism-related genes should be studied using molecular genetic tools to identify candidate genes for future treatment and control of strongyloidiasis. Unlike in C. elegans, there is lack of robust and effective functional genomic and genetic tools for most of the parasitic nematodes. However, the anatomical and morphological similarities of the $S$. stercoralis and $S$. ratti free-living females to $C$. elegans hermaphrodites have allowed researchers to adapt molecular genetic tools from C. elegans science to study basic biology and functional genomics in Strongyloides spp.

\section{The Proteomes}

Gastrointestinal parasitic nematodes release numerous proteins into their surroundings within the host. These constitute the excretory and secretory proteins (the ES proteome), which modulate the immune systems of their vertebrate hosts, allowing the parasitic stages of the worms to survive longer [94]. Excretory and secretory proteins are likely crucial in establishing and maintaining parasitism by nematodes at all stages of infection, including recognition of the host, tissue penetration, somatic migration, and immune evasion throughout these processes [94-97]. These essential functions make proteins of the ES secretome promising targets for drugs or vaccines. The excretory and secretory proteins of $S$. ratti are well studied compared to other Strongyloides spp. Soblik et al. [97] identified 586 proteins in the $S$. ratti secretome. Hunt et al. [88.0] identified 1266 proteins in the somatic proteomes of parasitic and free-living adult females of $S$. ratti. Of these, 569 are upregulated in parasitic adults and 409 proteins are upregulated in free-living adult females [88••, 92]. In addition, 882 ES proteins were also detected in this comparison, and $13 \%$ of the parasitic female ES proteins were products of genes upregulated in the transcriptome comparison [88••]. The presence of 25 astacin, 14 SCP/TAPs, prolyl endopeptidases, acetylcholinesterase, and transthyretin-like proteins in the ES proteome is consistent with upregulation of their encoding transcripts in the $S$. ratti and $S$. stercoralis parasitic females [88*0]. A study of the secretome of $S$. venezuelensis, an obligate gastrointestinal parasite of rats, identified 436 proteins from iL3s and 196 proteins from parasitic females [98]. From those identified proteins, 350 were specific to iL3s and 106 were specific to the parasitic adult females, whereas 86 proteins were common to iL3s and parasitic adult females including proteins that contain astacin and CAP domains [98]. Most proteins secreted by $S$. venezuelensis iL3s are peptidases or are predicted to act in embryonic development and oxidation-reduction processes. Most ES proteins from parasitic female $S$. venezuelensis are associated with glycolysis or DNA binding [98].

Despite the efforts cited above, the functions and biological significance of most of the ES proteins from $S$. ratti, $S$. stercoralis, and $S$. venezuelensis remain largely unknown. Notable exceptions are two galectins, $S r$-GAL-1 and $S r$-GAL3, excreted-secreted by $S$. ratti [96]. Galectins are a large group of $\beta$-galactoside-binding proteins which are involved in several biological processes especially in host-parasite interactions. The $S$. ratti galectins promoted release of the type 2 cytokines thymic stromal lymphopoietin and IL-22 from mucosal cells, supporting their immunoregulatory functions. They also stimulated cell migration in a dose-dependent manner [96]. Further studies to identify the biological functions of other salient ES proteins in parasitic females and iL3 stages of Strongyloides spp. would benefit the systematic search for anthelmintic drug targets.

\section{The Microbiomes}

The gastrointestinal tracts of mammals are colonized by thousands of bacterial, viral, and fungal species that constitute the microbiota. The microbiota has important functions in gut physiology, metabolism, immunity, and maintenance of the gut epithelial barrier [99, 100]. These beneficial effects largely depend on complex, mutualistic interactions between the gut microbiota, the host intestinal epithelium, and the host immune system [99, 101]. Parasitic helminths have adverse 
effects on the gastrointestinal tract of their hosts, altering of the gut ecosystem, including the composition of the microbiome, and epithelial barrier function through effects on mucus production and composition [101-103]. Helminths modify the host microbiome through the direct antimicrobial activity of their ES products [104]. Parasitic nematode infections can last for years owing to the ability of the worms to manipulate mammalian immune responses and thereby avoid immune-mediated expulsion [105]. Modulation of mammalian immune responses by helminths can also affect host immunity to concurrent infections resulting in impaired immunity to co-infection with various microbial pathogens in both humans [106] and in murine models [107, 108]. The presence of helminths in the gastrointestinal tract can alter both nutrient content and niche availability in this environment by impairing epithelial glucose absorption, which favors microbiota species that ferment sugars [109].

Like other helminths, Strongyloides spp. also exert immunomodulatory effects on their hosts $[110,111]$. However, there have been relatively few studies to date of the effects of Strongyloides infection on the composition of the host microbiome. Comparison of fecal microbiomes from $S$. stercoralis-infected and noninfected human subjects in northern Italy revealed a significant increase in alpha diversities and a significant decrease in beta diversities in the infected individuals [112]. In addition, S. stercoralis infection was also associated with expansion and enrichment of Leuconostocaceae, Ruminococcaceae, Paraprevotellaceae, and Peptococcus and reduced Pseudomonadales populations compared to the samples from the uninfected subjects [112]. Longitudinal study of fecal microbiomes over the course of S. venezuelensis infection in mice [113] revealed that the abundances of several bacterial taxa in the host intestinal microbiome changed significantly as the infection progressed, with an increase in the genera Bacteroides Candidatus and Arthromitus and a decrease in the populations of Prevotella and Rikenellaceae. Notably, the compositions of the microbiota of $S$. venezuelensis-infected mice reverted to the preinfection state once the parasites were cleared from the host, suggesting that parasite-induced changes are reversible [113]. Further detailed comparative microbiome studies need to be conducted in S. stercoralis and S. ratti using rodent models in order to understand into the contributions of the host microbiome to the outcomes of $S$. stercoralis autoinfection, hyperinfection, and dissemination.

\section{Manipulating the Genome}

\section{Transgenesis}

The free-living generation of Strongyloides spp. provides access to the adult germlines of these parasites enabling gene transfer into germ cell nuclei by microinjection of transgene DNA into gonadal syncytia (reviewed in [62]) using methods developed for C. elegans [114-118]. Briefly, transgeneencoding plasmid vectors are expressed in tissue-specific patterns in $\mathrm{F}_{1}$ larval progeny of microinjected $S$. stercoralis and $S$. ratti [119-122]. Although robustly expressed in the $\mathrm{F}_{1}$ generation, these transgene sequences, which are presumed to incorporated into multicopy episomal arrays as they are in C. elegans, are silenced in subsequent generations [119]. However, integration of transgene sequences into the chromosomes of Strongyloides spp., either by means of a transposon such as piggyBac [68] or by CRISPR/Cas9 [61••], enables continuous transgene expression through sequential generations of host and culture passage and the establishment of stable transgenic lines of $S$. ratti $[61 \bullet \cdot, 68]$. It is noteworthy that CRISPR/Cas9 allows integration single-copy transgenes into precise genomic loci, constituting an advantage over transposon-based methods which, in the case of piggy Bac, integrate many copies into random genomic loci, creating the possibility of confounding effects due to random insertional mutagenesis. Transient expression of transgene constructs in the $F_{1}$ generation following gene transfer has been exploited to assess anatomical patterns of the expression of specific genes in $S$. stercoralis, including those encoding the RIO kinases of this parasite as discussed above [85-87].

The gonad of free-living $S$. stercoralis males also has a syncytial region, and microinjection of plasmid-based transgene vectors results in a transformation of a proportion of spermatocytes and maturing spermatozoa, which are transmitted to $F_{1}$ progeny from crosses of microinjected males and nonmicroinjected females [38•]. Notably, crosses between free-living male $S$. stercoralis microinjected with a construct encoding a reporter transgene encoding green fluorescent protein and free-living females microinjected with a red fluorescent protein-encoding reporter yield a proportion of progeny expressing both reporters indicating contributions from both transduced parents [38•]. This discovery may provide the basis for generating homozygous mutations by CRISPR/Cas9, which is a newly developed capability in Strongyloides spp. discussed in the following section.

\section{CRISPR/Cas9}

Arguably the most significant advancement in the 5 years that have elapsed since the last review of this topic in Current Tropical Medicine Reports is the demonstration of targeted mutagenesis in $S$. stercoralis and $S$. ratti by CRISPR/Cas9 $[61 \bullet \bullet, 62]$. Reliable systems for transgenesis in these parasites enabled the transfer of genes encoding the Cas9 endonuclease, specific and control guide RNAs, disrupting insert sequences and selectable fluorescent markers into the germlines of freeliving female worms. This process created double-stranded breaks (DSB) in precise loci within target genes such as $\mathrm{SS}_{-}$ 
$u n c-22$ and $S s-d a f-16$ and allowed DNA sequences containing stop codons and terminal arms homologous to sequences flanking the site of the DSB to be inserted into these loci by homology-directed repair $[61 \bullet \bullet, 62]$. Since all $\mathrm{F}_{1}$ progeny of free-living $S$. stercoralis and $S$. ratti adults must infect a host to continue their life cycles, mutant progeny cannot be propagated in culture. Consequently, mutant genotypes must be confirmed in individual Strongyloides larvae following phenotyping. The necessity for post hoc genotyping makes studies of putative CRISPR/Cas9 mutants in Strongyloides spp. more challenging and labor intensive than comparable studies in $C$. elegans, but the demonstrated feasibility of this technique nevertheless represents a major achievement in functional genomics for parasitic nematodes. In addition to initial reports of targeted mutagenesis in Strongyloides spp. using CRISPR/Cas9, the feasibility of this approach was demonstrated by Bryant et al. [56•] in using CRISPR/Cas9 mutagenesis to show that the neuronal cGMP-gated calcium channel TAX-4 is necessary to mediate thermotaxis in S. stercoralis.

\section{Manipulating Gene Expression}

\section{RNA Interference}

RNA interference (RNAi) is a biological process in which a double-stranded RNA molecule inhibits transcriptional and post-transcriptional gene expression $[123,124]$. The natural functions of RNAi and its related processes are to protect the genome against the invasion of mobile genetic elements such as viruses and transposons [125]. RNAi has been harnessed as a tool to study the functions of genes in a wide range of organisms [126]. In experimental RNAi, double-stranded RNA (dsRNA) complementary to a portion of a gene of interest is administered to the subject via a variety of methods. dsRNA is processed into small interfering RNAs (siRNAs), which bind to the endogenous mRNA, forming a mRNAsiRNA duplexes and recruiting the RNA interfering specificity complex (RISC), which degrades/suppresses the target mRNA [126, 127]. The whole process results in the cessation/reduction of the effective function of the gene, which may result in informative phenotypes [126]. In nematodes, dsRNA/siRNA can be delivered by injection [128], soaking [129], feeding [130], and electroporation [131, 132]. The first successful use of RNAi in a gastrointestinal nematode parasite was reported in Nippostrongylus brasiliensis, a gastrointestinal parasite of the rat [133]. Subsequently, RNAi effects were reported in Onchocerca volvulus [134], Haemonchus contortus [131], Ostertagia ostertagi [135], Ascaris suum [136], and Trichostrongylus colubriformis [132]. In some cases, reduced target transcript levels were correlated with phenotypic changes in the subject parasitic nematodes. However, overall, RNAi effects on animal parasitic nematodes have been inconsistent, with variable results obtained between subject species, target genes, and experiments [137-140]. RNAi is apparently more efficient as an experimental tool in plant parasitic nematodes than in animal parasitic nematodes [138, 141].

Until recently, there have been no reports of informative RNAi effects in Strongyloides spp., regardless of the mode of delivery or configuration of the administered RNAi triggers. However, successful RNAi-mediated gene silencing was reported recently for $S$. ratti [142]. In this report, post parasitic $S$. ratti $\mathrm{L} 1$ were incubated at $19^{\circ} \mathrm{C}$ for up to 4 days in RNAi culture medium which contains DMEM, octopamine (20 mM), Sr-DAF-12 siRNA (10 mM), and RNAse out followed by phenotyping and quantification of $S r$-daf- 12 transcripts by qRT-PCR. Sr-DAF-12 knockdown significantly reduced the proportion of infective larvae arising from the homogonic or direct cycle from $12.67 \%$ in controls to $1.67 \%$ in worms undergoing $S r-D A F-12$-specific RNAi. Free-living female $S$. ratti derived from $S r$-DAF-12 RNAiexposed L1 produced fewer progeny than controls, and these grew more slowly and/or were less able to complete development to iL3 than controls [142]. Some larvae subjected to Ss-DAF-12 knockdown developed to iL3 and were able to infect a susceptible host but exhibited low reproductive potential and shortened duration of infection compared to controls. Consistent with the regulatory function of $S s$-DAF-12 in Strongyloides fat metabolism [142], Sr-DAF-12 RNAi knockdown also shifted aerobic fat metabolism toward anaerobic pathways. Previously, the application of exogenous $\Delta 7$ dafachronic acid to $S$. papillosus and $S$. stercoralis post freeliving larvae prevented development to iL3s suggesting the importance of DAF-12 and its ligand DA in the formation and metabolism of iL3s [66••, 77, 78, 81, 82]. Consistency and reproducibility have been significant issues in the application of experimental RNAi in animal parasitic nematodes [137-139]. It is very important to build upon the $S s-D A F-12$ study to optimize RNAi methods in Strongyloides spp. to obtain efficient knockdown and robust results to study the putative biological functions of parasitism genes, which could serve as candidate genes for future drug and vaccine targets.

\section{Expression of Dominant Interfering Transgenes}

Assessing phenotypes produced by expression of dominant transgenes designed to either suppress or augment expression of their endogenous counterparts represents an alternative to transcriptional silencing of target genes by RNAi or their direct disruption or editing by CRISPR/Cas9 as methods of assessing gene function in parasitic nematodes. This approach was used to infer the requirement for the insulin-regulated transcription factor $S s$-DAF-16 in the morphogenesis of the S. stercoralis iL3 [143] and has been used more recently to demonstrate the requirement for the catalytic activity of the 
RIO kinase $S$-RIOK-1 in development and survival of post free-living $S$. stercoralis larvae [87]. As previously discussed [144], both these studies involved transgenes designed to encode variants of their endogenous counterparts that retained the capacity to bind either genomic response elements in the case of $S s$-DAF-16 or substrate in the case of $S s$-RIOK-1 while having their functional domains ablated by mutation. It was assumed that plasmid-encoded transgenes are overexpressed in S. stercoralis by virtue of their being incorporated into multicopy episomal arrays. Thus, they outcompete the endogenous gene product of interest for binding partners but lack the capacity to execute their putative functions. In the case of $S_{S}$-RIOK-1, kinase activity of the dominant interfering transgene product was ablated by introducing a D282A mutation in sequence encoding its catalytic site; sequence encoding the substrate binding domain was left intact. Expressing this construct led to severe decrements in development and survivorship in worms expressing the dominant mutant construct [87], and these phenotypes were rescued with a frequency proportional to the expression level of a co-transformed transgene encoding wild-type $S s$-RIOK-1.

\section{Molecular Diagnosis}

Molecular diagnostic methods for human strongyloidiasis are based on the detection of parasite-specific DNA from stool, urine, and sputum samples using conventional PCR, nested PCR, and real-time PCR techniques [51, 145-147]. Usually, molecular diagnosis of Strongyloides spp. is done using the nuclear genetic markers such as the $18 \mathrm{~S}$ ribosomal RNA gene (18S rDNA, also called SSU) or the mitochondrial marker, cytochrome $c$ oxidase 1 ( $\operatorname{cox} 1)$. The $18 \mathrm{~S}$ rRNA sequence is highly conserved in Strongyloides spp. and widely used for molecular taxonomy [148, 149]. Hasegawa et al. [150] reported several nucleotide polymorphisms among different species of Strongyloides in the four of the HVRs of the 18S rDNA. The nucleotide arrangements of a HVR-IV are speciesspecific and preferred as a molecular genetic marker for Strongyloides spp. identification and diagnosis [150]. In the HVR-I and the rest of the HVRs, some intraspecies variability has been reported in $S$. stercoralis and $S$. fuelleborni isolated from humans, dogs, and nonhuman primates [4, 46, 50]. Hasegawa et al. [46] also stressed the importance of the mitochondrial cox 1 gene to identify cryptic variations in Strongyloides spp. isolated from different geographic locations and host species.

Compared to the other diagnostic methods, molecular diagnostic techniques are highly specific. However, the sensitivity of these methods is greatly affected by the type and number of biological samples subjected to PCR and the length of the PCR fragments amplified and sequenced to identify parasite larvae in the samples. For example, each larval stage has a different quantity of DNA, and notably, eggs have very low DNA content. The Strongyloides cuticle may be very difficult to lyse, so optimizing DNA extraction techniques for each larval stage is also essential $[15 \bullet \bullet, 16,50]$. In general, it is crucial to isolate worms from stool and other biological samples using an appropriate parasitological technique prior to DNA extraction in order to obtain DNA of sufficient quality and quantity for sensitive molecular diagnosis of Strongyloides spp. For definitive molecular identification and diagnosis, sequencing larger nuclear regions and whole mitochondrial genomes provides more relevant information than partial $18 \mathrm{~S}$ rDNA and mitochondrial genetic markers. Sequencing whole genomes of individual worms would provide much more sequence and genetic information than using partial sequences of $18 \mathrm{~S}$ rDNA and cox 1 for the molecular identification and diagnosis of Strongyloides spp. [15, 16].

\section{Conclusion}

Strongyloidiasis, due primarily to $S$. stercoralis, affects more than 370 million people worldwide mainly in tropical and subtropical regions but is generally regarded as the most neglected soil-borne tropical disease. In the 5 years preceding this publication, groundbreaking accomplishments in genome sequencing and annotation, transcriptomics, and proteomics have facilitated the application of modern functional genomic methods such as transgenesis, CRISPR/Cas9, and RNAi to studies of Strongyloides spp. These new capabilities have already been brought to bear on functional studies of genes necessary for motor function such as $S s-u n c-22$, genes essential for cellular signal transduction such as $\mathrm{Ss}$-daf-12 and $\mathrm{Ss}$ daf-16, genes involved in thermosensation such as Ss-tax-4, and the $S$ s-riok genes, which are associated with ribosomal genesis and function. Detailed studies of sex determination mechanisms and of germline organization in Strongyloides spp. have similarly uncovered unique features within this genus that may constitute specific adaptations to parasitism. Aside from their significant findings, these investigations underscore the power of Strongyloides spp. as models for the study of parasitic nematodes at the molecular and cellular levels. Well-annotated genomic resources have also contributed significantly to studies of the phylogeny and systematics of Strongyloides spp., uncovering evidence cryptic speciation within S. stercoralis sensu lato that has given rise to a canine-specific form and another one shared between dogs and humans that highlights the zoonotic potential of canine Strongyloides infections and calls for $S$. stercoralis-infected dogs to be treated as an adjunct to mass drug administration programs to control soil-transmitted helminths in humans. Finally, studies of steroid hormone signaling through the $\mathrm{SS}_{S}$ DAF-12 nuclear receptor have bolstered this pathway as a novel chemotherapeutic target in strongyloidiasis and perhaps other parasitic nematode infections. Among the many future 
research priorities in molecular and cellular biology and in ecology and epidemiology that are suggested by the accomplishments reviewed here are refining the CRISPR/Cas9 platform to allow precise sequence editing as well as gene disruption and to provide for host passage of worms carrying mutations in developmental regulatory genes and others affecting establishment in the mammalian host, better annotation of the S. papillosus genome, molecular surveillance to determine the prevalence and geographic distribution of zoonotic forms of S. stercoralis transmitted from dogs and other canids, and medicinal chemistry to improve drug-like characteristics of the dafachronic acid ligands of DAF-12 and promote their use as anthelmintic leads.

Funding Information The authors have received support from grants AI050668, AI105865, and AI144572 from the US National Institutes of Health.

\section{Compliance with Ethical Standards}

The use of animals to gather unpublished data cited in this paper was as stipulated in protocols 804798 and 804883 , which were approved by the Institutional Animal Care and Use Committee of the University of Pennsylvania. Animal use was in strict accordance with the standards set forth in the Guide for the Care and Use of Laboratory Animals of the US National Institutes of Health [151].

Conflict of Interest The authors declare that they have no conflicts of interest.

Open Access This article is distributed under the terms of the Creative Commons Attribution 4.0 International License (http:// creativecommons.org/licenses/by/4.0/), which permits unrestricted use, distribution, and reproduction in any medium, provided you give appropriate credit to the original author(s) and the source, provide a link to the Creative Commons license, and indicate if changes were made.

\section{References}

Papers of particular interest, published recently, have been highlighted as:

- Of importance

•• Of major importance

1. Krolewiecki A, Nutman TB. Strongyloidiasis: a neglected tropical disease. Infect Dis Clin N Am. 2019;33(1):135-51. https://doi. org/10.1016/j.idc.2018.10.006.

2. White MAF, Whiley H, Ross KE. A review of Strongyloides spp. environmental sources worldwide. Pathogens. 2019;8(3). https:// doi.org/10.3390/pathogens8030091.

3. Frias L, Stark DJ, Lynn MS, Nathan SK, Goossens B, Okamoto $\mathrm{M}$, et al. Lurking in the dark: cryptic Strongyloides in a Bornean slow loris. Int J Parasitol Parasites Wildl. 2018;7(2):141-6. https:// doi.org/10.1016/j.ijppaw.2018.03.003.

4. Hasegawa H, Kalousova B, McLennan MR, Modry D, Profousova-Psenkova I, Shutt-Phillips KA, et al. Strongyloides infections of humans and great apes in Dzanga-Sangha Protected Areas, Central African Republic and in degraded forest fragments in Bulindi, Uganda. Parasitol Int. 2016;65(5 Pt A):36770. https://doi.org/10.1016/j.parint.2016.05.004.

5. Thanchomnang T, Intapan PM, Sanpool O, Rodpai R, Tourtip S, Yahom S, et al. First molecular identification and genetic diversity of Strongyloides stercoralis and Strongyloides fuelleborni in human communities having contact with long-tailed macaques in Thailand. Parasitol Res. 2017;116(7):1917-23. https://doi.org/10. 1007/s00436-017-5469-z.

6. Bisoffi Z, Buonfrate D, Montresor A, Requena-Mendez A, Munoz J, Krolewiecki AJ, et al. Strongyloides stercoralis: a plea for action. PLoS Negl Trop Dis. 2013;7(5):e2214. https://doi.org/10. 1371/journal.pntd.0002214.

7. Schar F, Trostdorf U, Giardina F, Khieu V, Muth S, Marti H, et al. Strongyloides stercoralis: global distribution and risk factors. PLoS Negl Trop Dis. 2013;7(7):e2288. https://doi.org/10.1371/ journal.pntd.0002288.

8. Tamarozzi F, Martello E, Giorli G, Fittipaldo A, Staffolani S, Montresor A, et al. Morbidity associated with chronic Strongyloides stercoralis infection: a systematic review and meta-analysis. Am J Trop Med Hyg. 2019;100(6):1305-11. https:// doi.org/10.4269/ajtmh.18-0895.

9. Wulcan JM, Dennis MM, Ketzis JK, Bevelock TJ, Verocai GG. Strongyloides spp. in cats: a review of the literature and the first report of zoonotic Strongyloides stercoralis in colonic epithelial nodular hyperplasia in cats. Parasit Vectors. 2019;12(1):349. https://doi.org/10.1186/s13071-019-3592-7.

10. Basso W, Grandt LM, Magnenat AL, Gottstein B, Campos M. Strongyloides stercoralis infection in imported and local dogs in Switzerland: from clinics to molecular genetics. Parasitol Res. 2019;118(1):255-66. https://doi.org/10.1007/s00436-018-61733.

11. Sanchez-Thevenet P, Carmena D, Adell-Aledon M, Dacal E, Arias E, Saugar JM, et al. High prevalence and diversity of zoonotic and other intestinal parasites in dogs from eastern Spain. Vector Borne Zoonotic Dis. 2019. https://doi.org/10.1089/vbz.2019.2468.

12. Thanchomnang T, Intapan PM, Sanpool O, Rodpai R, Sadaow L, Phosuk I, et al. First molecular identification of Strongyloides fuelleborni in long-tailed macaques in Thailand and Lao People's Democratic Republic reveals considerable genetic diversity. J Helminthol. 2019;93(5):608-15. https://doi.org/10.1017/ S0022149X18000512.

13. Thamsborg SM, Ketzis J, Horii Y, Matthews JB. Strongyloides spp. infections of veterinary importance. Parasitology. $2017 ; 144(3): 274-84$. https://doi.org/10.1017/ S0031182016001116.

14. Shoop WL, Michael BF, Eary CH, Haines HW. Transmammary transmission of Strongyloides stercoralis in dogs. J Parasitol. 2002;88(3):536-9. https://doi.org/10.1645/0022-3395(2002) 088[0536:TTOSSI]2.0.CO;2.

15.• Jaleta TG, Zhou S, Bemm FM, Schar F, Khieu V, Muth S, et al. Different but overlapping populations of Strongyloides stercoralis in dogs and humans-dogs as a possible source for zoonotic strongyloidiasis. PLoS Negl Trop Dis. 2017;11(8):e0005752. https:// doi.org/10.1371/journal.pntd.0005752 This Cambodia-based study is the first to discover genetic evidence of natural zoonotic transmission of $S$. stercoralis between domestic dogs and humans. Within a natural field setting, the authors report genetically distinct populations of $S$. stercoralis that are dogspecific, human-specific and shared between dogs and humans. Intriguingly, there was no evidence of hybridization between these populations despite co-occurrence of their freeliving adult stages in soils underlying individual dwellings.

16. Kikuchi T, Hino A, Tanaka T, Aung MP, Afrin T, Nagayasu E, et al. Genome-wide analyses of individual Strongyloides 
stercoralis (Nematoda: Rhabditoidea) provide insights into population structure and reproductive life cycles. PLoS Negl Trop Dis. 2016;10(12):e0005253. https://doi.org/10.1371/journal.pntd. 0005253.

17. Nagayasu E, Aung M, Hortiwakul T, Hino A, Tanaka T, Higashiarakawa M, et al. A possible origin population of pathogenic intestinal nematodes, Strongyloides stercoralis, unveiled by molecular phylogeny. Sci Rep. 2017;7(1):4844. https://doi.org/ 10.1038/s41598-017-05049-x.

18. Grove DI. Human strongyloidiasis. Adv Parasitol. 1996;38:251309

19. DiGiulio M. Strongyloidiasis. J Nurs Pract. 2019;15:438-43. https://doi.org/10.1016/j.nurpra.2019.03.015.

20. Puthiyakunnon S, Boddu S, Li Y, Zhou X, Wang C, Li J, et al. Strongyloidiasis - an insight into its global prevalence and management. PLoS Negl Trop Dis. 2014;8(8):e3018. https://doi.org/ 10.1371/journal.pntd.0003018.

21. Vasquez-Rios G, Pineda-Reyes R, Pineda-Reyes J, Marin R, Ruiz EF, Terashima A. Strongyloides stercoralis hyperinfection syndrome: a deeper understanding of a neglected disease. J Parasit Dis. 2019;43(2):167-75. https://doi.org/10.1007/s12639-01901090-x.

22. Cervone M, Giannelli A, Otranto D, Perrucci S. Strongyloides stercoralis hyperinfection in an immunosuppressed dog. Prat medicale Chir l'animal Cie. 2016;51:55-9. https://doi.org/10. 1016/j.anicom.2016.05.001.

23. Chan FLY, Kennedy B, Nelson R. Fatal Strongyloides hyperinfection syndrome in an immunocompetent adult with review of the literature. Intern Med J. 2018;48(7):872-5. https://doi. org/10.1111/imj.13940.

24. Siddiqui AA, Berk SL. Diagnosis of Strongyloides stercoralis infection. Clin Infect Dis. 2001;33(7):1040-7. https://doi.org/10. 1086/322707.

25. Kim J, Joo HS, Ko HM, Na MS, Hwang SH, Im JC. A case of fatal hyperinfective strongyloidiasis with discovery of autoinfective filariform larvae in sputum. Korean J Parasitol. 2005;43(2):51-5. https://doi.org/10.3347/kjp.2005.43.2.51.

26. Malnick S, Somin M, Beilinson N, Basevitch A, Bregman G, Zimhony O. Strongyloides hyperinfection in Ethiopian immigrants in Israel. Isr Med Assoc J. 2009;11(11):660-3.

27. Grove DI. Strongyloidiasis: a conundrum for gastroenterologists. Gut. 1994;35(4):437-40. https://doi.org/10.1136/gut.35.4.437.

28. Lok JB. Strongyloides stercoralis and relatives: recent advances in general and molecular biology. Curr Trop Med Rep. 2014;1(4): 194-206.

29. Streit A. Genetics: modes of reproduction and genetic analysis. Parasitology. 2017;144(3):316-26. https://doi.org/10.1017/ S0031182016000342.

30. Jaleta TG, Rodelsperger C, Streit A. Parasitological and transcriptomic comparison of Strongyloides ratti infections in natural and in suboptimal permissive hosts. Exp Parasitol. 2017;180: 112-8. https://doi.org/10.1016/j.exppara.2016.12.003.

31. Viney M. Strongyloides. Parasitology. 2017;144(3):259-62. https://doi.org/10.1017/S0031182016001773.

32. Yamada M, Matsuda S, Nakazawa M, Arizono N. Speciesspecific differences in heterogonic development of serially transferred free-living generations of Strongyloides planiceps and Strongyloides stercoralis. J Parasitol. 1991;77(4):592-4.

33. Mejia R, Nutman TB. Screening, prevention, and treatment for hyperinfection syndrome and disseminated infections caused by Strongyloides stercoralis. Curr Opin Infect Dis. 2012;25(4):45863. https://doi.org/10.1097/QCO.0b013e3283551dbd.

34. Hubbard EJ, Greenstein D. Introduction to the germ line. In: WormBook, editor. The C. elegans Research Community: WormBook; 2005. p. 1-4. https://doi.org/10.1895/wormbook.1. 18.1.35.
35. Kimble J, Crittenden SL. Germline proliferation and its control. In: WormBook, editor. The C. elegans Research Community: WormBook; 2005. p. 1-14. https://doi.org/10.1895/wormbook.1. 13.1.

36. Rudel D, Riebesell M, Sommer RJ. Gonadogenesis in Pristionchus pacificus and organ evolution: development, adult morphology and cell-cell interactions in the hermaphrodite gonad. Dev Biol. 2005;277(1):200-21. https://doi.org/10.1016/j. ydbio.2004.09.021.

37. Kulkarni A, Lightfoot JW, Streit A. Germline organization in Strongyloides nematodes reveals alternative differentiation and regulation mechanisms. Chromosoma. 2016;125(4):725-45. https://doi.org/10.1007/s00412-015-0562-5 This comparative study of germline organization and fluid dynamics uncovered striking differences in the temporal patterns of germ cell proliferation in Strongyloides spp. and the model nematode Caenorhabditis elegans. Chiefly, this event is restricted to early and mid-larval development in the parasites. Divergent patterns in the epigenetic regulation of gene expression during germline development were also discovered in comparisons of six nematode species.

38. Shao H, Li X, Lok JB. Heritable genetic transformation of Strongyloides stercoralis by microinjection of plasmid DNA constructs into the male germline. Int J Parasitol. 2017;47(9):511-5. https://doi.org/10.1016/j.ijpara.2017.04.003 This study is the first to demonstrate transgenesis in a parasitic nematode by specifically targeting the male germline. It also provided additional evidence that free-living male $S$. stercoralis transfer paternal genes during mating. Male mating behavior also provides a means of dispersing paternal transgenes to progeny of multiple females, thereby increasing efficiency of transgenesis. Inheritance of transgenes from both parents was demonstrated, providing a mechanism for rendering heterozygous CRISPR/Cas9-induced mutations homozygous.

39. Kulkarni A, Dyka A, Nemetschke L, Grant WN, Streit A. Parastrongyloides trichosuri suggests that $\mathrm{XX} / \mathrm{XO}$ sex determination is ancestral in Strongyloididae (Nematoda). Parasitology. 2013;140(14):1822-30. https://doi.org/10.1017/ S0031182013001315.

40. Harvey SC, Viney ME. Sex determination in the parasitic nematode Strongyloides ratti. Genetics. 2001;158(4):1527-33.

41. Nemetschke L, Eberhardt AG, Viney ME, Streit A. A genetic map of the animal-parasitic nematode Strongyloides ratti. Mol Biochem Parasitol. 2010;169(2):124-7. https://doi.org/10.1016/j. molbiopara.2009.10.008.

42. Nemetschke L, Eberhardt AG, Hertzberg H, Streit A. Genetics, chromatin diminution, and sex chromosome evolution in the parasitic nematode genus Strongyloides. Curr Biol. 2010;20(19): 1687-96. https://doi.org/10.1016/j.cub.2010.08.014.

43. Holz A, Streit A. Gain and loss of small RNA classescharacterization of small RNAs in the parasitic nematode family Strongyloididae. Genome Biol Evol. 2017;9(10):2826-43. https://doi.org/10.1093/gbe/evx197.

44. Hunt VL, Hino A, Yoshida A, Kikuchi T. Comparative transcriptomics gives insights into the evolution of parasitism in Strongyloides nematodes at the genus, subclade and species level. Sci Rep. 2018;8(1):5192. https://doi.org/10.1038/s41598-01823514-z.

45. Crook M, Viney ME. The effect of non-immune stresses on the development of Strongyloides ratti. Parasitology. 2005;131(Pt 3): 383-92.

46. Hasegawa H, Sato H, Fujita S, Nguema PP, Nobusue K, Miyagi K, et al. Molecular identification of the causative agent of human strongyloidiasis acquired in Tanzania: dispersal and diversity of Strongyloides spp. and their hosts. Parasitol Int. 2010;59(3):40713. https://doi.org/10.1016/j.parint.2010.05.007. 
47. Paradies P, Buonfrate D, Iatta R, Iarussi F, Giorli G, Palmieri VO, et al. Efficacy of ivermectin to control Strongyloides stercoralis infection in sheltered dogs. Acta Trop. 2019;190:204-9. https:// doi.org/10.1016/j.actatropica.2018.11.014.

48. Wilson A, Fearon D. Paediatric strongyloidiasis in central Australia. Trop Med Infect Dis. 2018;3(2). https://doi.org/10. 3390/tropicalmed3020064.

49. Umur S, Meral Y, Bolukbas CS, Gurler AT, Acici M. First clinical Strongyloides stercoralis case in a dog in Turkey. Turk J Vet Anim Sci. 2017;41:312-5. https://doi.org/10.3906/vet-1606-2.

50. Schar F, Guo L, Streit A, Khieu V, Muth S, Marti H, et al. Strongyloides stercoralis genotypes in humans in Cambodia. Parasitol Int. 2014;63(3):533-6. https://doi.org/10.1016/j.parint. 2014.01.010.

51. Laymanivong S, Hangvanthong B, Insisiengmay B, Vanisaveth V, Laxachack P, Jongthawin J, et al. First molecular identification and report of genetic diversity of Strongyloides stercoralis, a current major soil-transmitted helminth in humans from Lao People's Democratic Republic. Parasitol Res. 2016;115(8):2973-80. https://doi.org/10.1007/s00436-016-5052-z.

52. Eberhardt AG, Mayer WE, Bonfoh B, Streit A. The Strongyloides (Nematoda) of sheep and the predominant Strongyloides of cattle form at least two different, genetically isolated populations. Vet Parasitol. 2008;157(1-2):89-99. https://doi.org/10.1016/j.vetpar. 2008.07.019.

53. Castelletto ML, Gang SS, Okubo RP, Tselikova AA, Nolan TJ, Platzer EG, et al. Diverse host-seeking behaviors of skinpenetrating nematodes. PLoS Pathog. 2014;10(8):e1004305. https://doi.org/10.1371/journal.ppat.1004305.

54. Bryant AS, Hallem EA. Terror in the dirt: sensory determinants of host seeking in soil-transmitted mammalian-parasitic nematodes. Int J Parasitol Drugs Drug Resist. 2018;8(3):496-510. https://doi. org/10.1016/j.ijpddr.2018.10.008.

55. Gang SS, Hallem EA. Mechanisms of host seeking by parasitic nematodes. Mol Biochem Parasitol. 2016;208(1):23-32. https:// doi.org/10.1016/j.molbiopara.2016.05.007.

56. Bryant AS, Ruiz F, Gang SS, Castelletto ML, Lopez JB, Hallem EA. A critical role for thermosensation in host seeking by skinpenetrating nematodes. Curr Biol. 2018;28(14):2338-47 e6. https://doi.org/10.1016/j.cub.2018.05.063 This study represents the first application of CRISPR/Cas9 mutagenesis in a hypothesis-driven study of parasitic nematode biology. In it, the authors proved that the cyclic GMP-gated ion channel subunit $\mathrm{Ss}$-TAX-4 is required for thermotaxis in $\mathrm{S}$. stercoralis infective third-stage larvae. Thermotaxis is an essential component of host finding by these infective larvae, and so it constitutes a target for novel preventative interventions in human strongyloidiasis and possibly other soil-transmitted helminthiases.

57. Lee JH, Dillman AR, Hallem EA. Temperature-dependent changes in the host-seeking behaviors of parasitic nematodes. BMC Biol. 2016;14:36. https://doi.org/10.1186/s12915-016-0259-0.

58. Forbes WM, Ashton FT, Boston R, Zhu X, Schad GA. Chemoattraction and chemorepulsion of Strongyloides stercoralis infective larvae on a sodium chloride gradient is mediated by amphidial neuron pairs ASE and ASH, respectively. Vet Parasitol. 2004;120(3):189-98. https://doi.org/10.1016/j.vetpar. 2004.01.005.

59. Safer D, Brenes M, Dunipace S, Schad G. Urocanic acid is a major chemoattractant for the skin-penetrating parasitic nematode Strongyloides stercoralis. Proc Natl Acad Sci U S A. 2007;104(5):1627-30. https://doi.org/10.1073/pnas.0610193104.

60. Koga M, Nuamtanong S, Dekumyoy P, Yoonuan T, Maipanich W, Rojekittikhun W, et al. Host-finding behavior of Strongyloides stercoralis infective larvae to sodium cation, human serum, and sweat. Southeast Asian J Trop Med Public Health. 2005;36(Suppl 4):93-8.

61.• Gang SS, Castelletto ML, Bryant AS, Yang E, Mancuso N, Lopez JB, et al. Targeted mutagenesis in a human-parasitic nematode. PLoS Pathog. 2017;13(10):e1006675. https://doi.org/10.1371/ journal.ppat.1006675 This is the first comprehensive account of targeted mutagenesis in a parasitic nematode using CRISPR/Cas9. Among many salient accomplishments, it features workable protocols for insertional mutagenesis and post-hoc genotyping in $S$. stercoralis and $S$. ratti, documentation of an informative phenotype resulting from disruption of $S s-u n c-22$ and passage of mutant worms to rodent hosts.

62. Lok JB, Shao H, Massey HC, Li X. Transgenesis in Strongyloides and related parasitic nematodes: historical perspectives, current functional genomic applications and progress towards gene disruption and editing. Parasitology. 2017;144(3):327-42. https:// doi.org/10.1017/S0031182016000391.

63. Tsubokawa D, Hatta T, Kikuchi T, Maeda H, Mikami F, Alim MA, et al. Venestatin, a $\mathrm{Ca}(++)$-binding protein from the parasitic nematode Strongyloides venezuelensis, is involved in the larval migration process. Int J Parasitol. 2017;47(8):501-9. https://doi.org/10. 1016/j.ijpara.2017.01.008.

64. Nolan TJ, Megyeri Z, Bhopale VM, Schad GA. Strongyloides stercoralis: the first rodent model for uncomplicated and hyperinfective strongyloidiasis, the Mongolian gerbil (Meriones unguiculatus). J Infect Dis. 1993;168(6):1479-84.

65. Charuchaibovorn S, Sanprasert V, Nuchprayoon S. The experimental infections of the human isolate of Strongyloides stercoralis in a rodent model (the Mongolian gerbil, Meriones unguiculatus). Pathogens. 2019;8(1). https://doi.org/10.3390/pathogens8010021.

66.• Patton JB, Bonne-Annee S, Deckman J, Hess JA, Torigian A, Nolan TJ, et al. Methylprednisolone acetate induces, and Delta7dafachronic acid suppresses, Strongyloides stercoralis hyperinfection in NSG mice. Proc Natl Acad Sci U S A. 2018;115(1):204-9. https://doi.org/10.1073/pnas.1712235114 This study confirms the potential of DAF-12 nuclear receptor signaling as a novel therapeutic target in hyperinfective strongyloidiasis by demostrating that oral administration of the DAF-12 ligand $\Delta 7$-dafachronic acid suppresses populations of $S$. stercoralis autoinfective larvae. It is also significant in introducing a new murine model of human strongyloidiasis involving the severely immunocompromised NSG mouse. Significantly, this mouse can be engrafted with cells of the human immune system, enhancing its power as a model of human parasitism.

67. Shultz LD, Lyons BL, Burzenski LM, Gott B, Chen X, Chaleff S, et al. Human lymphoid and myeloid cell development in NOD/ LtSz-scid IL2R gamma null mice engrafted with mobilized human hemopoietic stem cells. J Immunol. 2005;174(10):6477-89. https://doi.org/10.4049/jimmunol.174.10.6477.

68. Shao H, Li X, Nolan TJ, Massey HC Jr, Pearce EJ, Lok JB. Transposon-mediated chromosomal integration of transgenes in the parasitic nematode Strongyloides ratti and establishment of stable transgenic lines. PLoS Pathog. 2012;8(8):e1002871. https://doi.org/10.1371/journal.ppat.1002871.

69. Viney M, Kikuchi T. Strongyloides ratti and S. venezuelensisrodent models of Strongyloides infection. Parasitology. 2017;144(3):285-94. https://doi.org/10.1017/ S0031182016000020.

70. Stiernagle T. Maintenance of C. elegans. In: WormBook, editor. The C. elegans Research Community: WormBook; 2006. p. 1-11. https://doi.org/10.1895/wormbook.1.101.1.

71. Dulovic A, Puller V, Streit A. Optimizing culture conditions for free-living stages of the nematode parasite Strongyloides ratti. Exp 
Parasitol. 2016;168:25-30. https://doi.org/10.1016/j.exppara. 2016.06.005.

72. Biewener V, Welz C, Khumpool G, Kuttler U, Schnieder T. Strongyloides papillosus: changes in transcript levels of lysozyme and aspartic protease 2 in percutaneously migrated larvae. Exp Parasitol. 2012;132(1):62-8. https://doi.org/10.1016/j.exppara. 2012.02.009.

73. Franke D, Strube C, Epe C, Welz C, Schnieder T. Larval migration in PERL chambers as an in vitro model for percutaneous infection stimulates feeding in the canine hookworm Ancylostoma caninum. Parasit Vectors. 2011;4:7. https://doi.org/10.1186/1756-3305-4-7.

74. Jannasch M, Groeber F, Brattig NW, Unger C, Walles H, Hansmann J. Development and application of three-dimensional skin equivalents for the investigation of percutaneous worm invasion. Exp Parasitol. 2015;150:22-30. https://doi.org/10.1016/j. exppara.2015.01.005.

75. Crook M. The dauer hypothesis and the evolution of parasitism: 20 years on and still going strong. Int J Parasitol. 2014;44(1):1-8. https://doi.org/10.1016/j.ijpara.2013.08.004.

76. Lok JB. Signaling in parasitic nematodes: physicochemical communication between host and parasite and endogenous molecular transduction pathways governing worm development and survival. Curr Clin Microbiol Rep. 2016;3(4):186-97. https://doi.org/10. 1007/s40588-016-0046-2.

77. Wang Z, Zhou XE, Motola DL, Gao X, Suino-Powell K, Conneely A, et al. Identification of the nuclear receptor DAF-12 as a therapeutic target in parasitic nematodes. Proc Natl Acad Sci U S A. 2009;106(23):9138-43. https://doi.org/10.1073/pnas. 0904064106.

78. Albarqi MM, Stoltzfus JD, Pilgrim AA, Nolan TJ, Wang Z, Kliewer SA, et al. Regulation of life cycle checkpoints and developmental activation of infective larvae in Strongyloides stercoralis by dafachronic acid. PLoS Pathog. 2016;12(1):e1005358. https:// doi.org/10.1371/journal.ppat.1005358.

79. Stoltzfus JD, Bart SM, Lok JB. cGMP and NHR signaling coregulate expression of insulin-like peptides and developmental activation of infective larvae in Strongyloides stercoralis. PLoS Pathog. 2014;10(7):e1004235. https://doi.org/10.1371/journal. ppat.1004235.

80. Motola DL, Cummins CL, Rottiers V, Sharma KK, Li T, Li Y, et al. Identification of ligands for DAF-12 that govern dauer formation and reproduction in C. elegans. Cell. 2006;124(6):120923. https://doi.org/10.1016/j.cell.2006.01.037.

81. Ogawa A, Streit A, Antebi A, Sommer RJ. A conserved endocrine mechanism controls the formation of dauer and infective larvae in nematodes. Curr Biol. 2009;19(1):67-71. https://doi.org/10.1016/ j.cub.2008.11.063.

82. Wang Z, Stoltzfus J, You YJ, Ranjit N, Tang H, Xie Y, et al. The nuclear receptor DAF-12 regulates nutrient metabolism and reproductive growth in nematodes. PLoS Genet. 2015;11(3):e1005027. https://doi.org/10.1371/journal.pgen.1005027.

83. Schroeder FC. Small molecule signaling in Caenorhabditis elegans. ACS Chem Biol. 2006;1(4):198-200. https://doi.org/ 10.1021/cb600173t.

84. Martin RJ. Nuclear option prevents hyperinfection in the Strongyloides worm war. Proc Natl Acad Sci U S A. 2018;115(1):9-11. https://doi.org/10.1073/pnas.1719538115.

85. Lei WQ, Lok JB, Yuan W, Zhang YZ, Stoltzfus JD, Gasser RB, et al. Structural and developmental expression of Ss-riok-2, an RIO protein kinase encoding gene of Strongyloides stercoralis. Sci Rep. 2017;7(1):8693. https://doi.org/10.1038/s41598-01707991-2.

86. Yuan W, Liu Y, Lok JB, Stoltzfus JD, Gasser RB, Lei W, et al. Exploring features and function of Ss-riok-3, an enigmatic kinase gene from Strongyloides stercoralis. Parasit Vectors. 2014;7:561. https://doi.org/10.1186/s13071-014-0561-z.
87. Yuan W, Zhou H, Lok JB, Lei W, He S, Gasser RB, et al. Functional genomic exploration reveals that $S s$-RIOK-1 is essential for the development and survival of Strongyloides stercoralis larvae. Int J Parasitol. 2017;47(14):933-40. https://doi.org/10. 1016/j.ijpara.2017.06.005.

88.• Hunt VL, Tsai IJ, Coghlan A, Reid AJ, Holroyd N, Foth BJ, et al. The genomic basis of parasitism in the Strongyloides clade of nematodes. Nat Genet. 2016;48(3):299-307. https://doi.org/10. 1038/ng.3495 This a comprehensive study of the genomes of four Strongyloides species, the related facultative parasite Parastrongyloides trichosuri and the free-living nematode Rhabditophanes spp. In addition to highlighting increasingly well annotated genomes for the Strongyloides clade, this study identified key gene families, most prominenatly the astacinlike and SCP/TAPS proteins, that are expanded in parasitic members of the clade. These putative "parasitism-related" genes are confirmed by trends in transcript abundance during transitions between their free-living and parasitic life cycles.

89. The C. elegans Consortium. Genome sequence of the nematode C. elegans: a platform for investigating biology. Science. 1998;282(5396):2012-8.

90. Dieterich C, Clifton SW, Schuster LN, Chinwalla A, Delehaunty K, Dinkelacker I, et al. The Pristionchus pacificus genome provides a unique perspective on nematode lifestyle and parasitism. Nat Genet. 2008;40(10):1193-8. https://doi.org/10.1038/ng.227.

91. Baskaran P, Jaleta TG, Streit A, Rodelsperger C. Duplications and positive selection drive the evolution of parasitism-associated gene families in the nematode Strongyloides papillosus. Genome Biol Evol. 2017;9(3):790-801. https://doi.org/10.1093/gbe/ evx040.

92. Hunt VL, Tsai IJ, Selkirk ME, Viney M. The genome of Strongyloides spp. gives insights into protein families with a putative role in nematode parasitism. Parasitology. 2017;144(3): 343-58. https://doi.org/10.1017/S0031182016001554.

93. Cantacessi C, Hofmann A, Young ND, Broder U, Hall RS, Loukas A, et al. Insights into SCP/TAPS proteins of liver flukes based on large-scale bioinformatic analyses of sequence datasets. PLoS One. 2012;7(2):e31164. https://doi.org/10.1371/journal.pone. 0031164.

94. Cuesta-Astroz Y, Oliveira FS, Nahum LA, Oliveira G. Helminth secretomes reflect different lifestyles and parasitized hosts. Int J Parasitol. 2017;47(9):529-44. https://doi.org/10.1016/j.ijpara. 2017.01.007.

95. Bennuru S, Semnani R, Meng Z, Ribeiro JM, Veenstra TD, Nutman TB. Brugia malayi excreted/secreted proteins at the host/parasite interface: stage- and gender-specific proteomic profiling. PLoS Negl Trop Dis. 2009;3(4):e410. https://doi.org/10. 1371/journal.pntd.0000410

96. Ditgen D, Anandarajah EM, Reinhardt A, Younis AE, Witt S, Hansmann J, et al. Comparative characterization of two galectins excreted-secreted from intestine-dwelling parasitic versus freeliving females of the soil-transmitted nematode Strongyloides. Mol Biochem Parasitol. 2018;225:73-83. https://doi.org/10. 1016/j.molbiopara.2018.08.008.

97. Soblik H, Younis AE, Mitreva M, Renard BY, Kirchner M, Geisinger F, et al. Life cycle stage-resolved proteomic analysis of the excretome/secretome from Strongyloides ratti-identification of stage-specific proteases. Mol Cell Proteomics. 2011;10(12):M111 010157. https://doi.org/10.1074/mcp.M111. 010157.

98. Maeda Y, Palomares-Rius JE, Hino A, Afrin T, Mondal SI, Nakatake A, et al. Secretome analysis of Strongyloides venezuelensis parasitic stages reveals that soluble and insoluble proteins are involved in its parasitism. Parasit Vectors. 2019;12(1):21. https://doi.org/10.1186/s13071-018-3266-X. 
99. Backhed F, Ley RE, Sonnenburg JL, Peterson DA, Gordon JI. Host-bacterial mutualism in the human intestine. Science. 2005;307(5717):1915-20. https://doi.org/10.1126/science. 1104816.

100. Fung TC, Olson CA, Hsiao EY. Interactions between the microbiota, immune and nervous systems in health and disease. Nat Neurosci. 2017;20(2):145-55. https://doi.org/10.1038/nn.4476.

101. Su C, Su L, Li Y, Long SR, Chang J, Zhang W, et al. Helminthinduced alterations of the gut microbiota exacerbate bacterial colitis. Mucosal Immunol. 2018;11(1):144-57. https://doi.org/10. 1038/mi.2017.20.

102. Leung JM, Graham AL, Knowles SCL. Parasite-microbiota interactions with the vertebrate gut: synthesis through an ecological lens. Front Microbiol. 2018;9:843. https://doi.org/10.3389/fmicb. 2018.00843.

103. Peachey LE, Jenkins TP, Cantacessi C. This gut ain't big enough for both of us. Or is it? Helminth-microbiota interactions in veterinary species. Trends Parasitol. 2017;33(8):619-32. https://doi. org/10.1016/j.pt.2017.04.004.

104. Brosschot TP, Reynolds LA. The impact of a helminth-modified microbiome on host immunity. Mucosal Immunol. 2018;11(4): 1039-46. https://doi.org/10.1038/s41385-018-0008-5.

105. Varyani F, Fleming JO, Maizels RM. Helminths in the gastrointestinal tract as modulators of immunity and pathology. Am J Physiol Gastrointest Liver Physiol. 2017;312(6):G537-G49. https://doi.org/10.1152/ajpgi.00024.2017.

106. Harris JB, Podolsky MJ, Bhuiyan TR, Chowdhury F, Khan AI, Larocque RC, et al. Immunologic responses to Vibrio cholerae in patients co-infected with intestinal parasites in Bangladesh. PLoS Negl Trop Dis. 2009;3(3):e403. https://doi.org/10.1371/journal. pntd.0000403.

107. Chen CC, Louie S, McCormick B, Walker WA, Shi HN. Concurrent infection with an intestinal helminth parasite impairs host resistance to enteric Citrobacter rodentium and enhances Citrobacter-induced colitis in mice. Infect Immun. 2005;73(9): 5468-81. https://doi.org/10.1128/IAI.73.9.5468-5481.2005.

108. Reynolds LA, Redpath SA, Yurist-Doutsch S, Gill N, Brown EM, van der Heijden J, et al. Enteric helminths promote Salmonella coinfection by altering the intestinal metabolome. J Infect Dis. 2017;215(8):1245-54. https://doi.org/10.1093/infdis/jix141.

109. Shea-Donohue T, Sullivan C, Finkelman FD, Madden KB, Morris $\mathrm{SC}$, Goldhill J, et al. The role of IL-4 in Heligmosomoides polygyrus-induced alterations in murine intestinal epithelial cell function. J Immunol. 2001;167(4):2234-9. https://doi.org/10. 4049/jimmunol.167.4.2234.

110. Bonne-Annee S, Hess JA, Abraham D. Innate and adaptive immunity to the nematode Strongyloides stercoralis in a mouse model. Immunol Res. 2011;51(2-3):205-14. https://doi.org/10.1007/ s12026-011-8258-2.

111. Breloer M, Abraham D. Strongyloides infection in rodents: immune response and immune regulation. Parasitology. 2017;144(3):295-315. https://doi.org/10.1017/ S0031182016000111.

112. Jenkins TP, Formenti F, Castro C, Piubelli C, Perandin F, Buonfrate D, et al. A comprehensive analysis of the faecal microbiome and metabolome of Strongyloides stercoralis infected volunteers from a non-endemic area. Sci Rep. 2018;8(1):15651. https://doi.org/10.1038/s41598-018-33937-3.

113. Afrin T, Murase K, Kounosu A, Hunt VL, Bligh M, Maeda Y, et al. Sequential changes in the host gut microbiota during infection with the intestinal parasitic nematode Strongyloides venezuelensis. Front Cell Infect Microbiol. 2019;9:217. https:// doi.org/10.3389/fcimb.2019.00217.

114. Fire A. Integrative transformation of Caenorhabditis elegans. EMBO J. 1986;5(10):2673-80.
115. Kimble J, Hodgkin J, Smith T, Smith J. Suppression of an amber mutation by microinjection of suppressor tRNA in C. elegans. Nature. 1982;299(5882):456-8.

116. Mello C, Fire A. DNA transformation. Methods Cell Biol. 1995;48:451-82.

117. Mello CC, Kramer JM, Stinchcomb D, Ambros V. Efficient gene transfer in C. elegans: extrachromosomal maintenance and integration of transforming sequences. EMBO J. 1991;10(12):3959-70.

118. Stinchcomb DT, Shaw JE, Carr SH, Hirsh D. Extrachromosomal DNA transformation of Caenorhabditis elegans. Mol Cell Biol. 1985;5(12):3484-96. https://doi.org/10.1128/mcb.5.12.3484.

119. Junio AB, Li X, Massey HC Jr, Nolan TJ, Todd Lamitina S, Sundaram MV, et al. Strongyloides stercoralis: cell- and tissuespecific transgene expression and co-transformation with vector constructs incorporating a common multifunctional 3' UTR. Exp Parasitol. 2008;118(2):253-65.

120. Li X, Massey HC, Nolan TJ, Schad GA, Kraus K, Sundaram M, et al. Successful transgenesis of the parasitic nematode Strongyloides stercoralis requires endogenous non-coding control elements. Int J Parasitol. 2006;36:671-9. https://doi.org/10.1016/j. ijpara.2005.12.007.

121. Li X, Shao H, Junio A, Nolan TJ, Massey HC Jr, Pearce EJ, et al. Transgenesis in the parasitic nematode Strongyloides ratti. Mol Biochem Parasitol. 2011;179(2):114-9. https://doi.org/10.1016/j. molbiopara.2011.06.002.

122. Lok JB, Massey HC Jr. Transgene expression in Strongyloides stercoralis following gonadal microinjection of DNA constructs. Mol Biochem Parasitol. 2002;119(2):279-84.

123. Agrawal N, Dasaradhi PV, Mohmmed A, Malhotra P, Bhatnagar RK, Mukherjee SK. RNA interference: biology, mechanism, and applications. Microbiol Mol Biol Rev. 2003;67(4):657-85. https:// doi.org/10.1128/mmbr.67.4.657-685.2003.

124. Grishok A. RNAi mechanisms in Caenorhabditis elegans. FEBS Lett. 2005;579(26):5932-9. https://doi.org/10.1016/j.febslet. 2005.08.001

125. Wilkins C, Dishongh R, Moore SC, Whitt MA, Chow M, Machaca K. RNA interference is an antiviral defence mechanism in Caenorhabditis elegans. Nature. 2005;436(7053):1044-7. https://doi.org/10.1038/nature03957.

126. Mello CC, Conte D Jr. Revealing the world of RNA interference. Nature. 2004;431(7006):338-42. https://doi.org/10.1038/ nature 02872

127. Wang J, Barr MM. RNA interference in Caenorhabditis elegans. Methods Enzymol. 2005;392:36-55. https://doi.org/10.1016/ S0076-6879(04)92003-4.

128. Fire A, Xu S, Montgomery MK, Kostas SA, Driver SE, Mello CC. Potent and specific genetic interference by double-stranded RNA in Caenorhabditis elegans. Nature. 1998;391(6669):806-11. https://doi.org/10.1038/35888.

129. Tabara H, Grishok A, Mello CC. RNAi in C. elegans: soaking in the genome sequence. Science. 1998;282(5388):430-1. https:// doi.org/10.1126/science.282.5388.430.

130. Timmons L, Fire A. Specific interference by ingested dsRNA. Nature. 1998;395(6705):854. https://doi.org/10.1038/27579.

131. Geldhof P, Murray L, Couthier A, Gilleard JS, McLauchlan G, Knox DP, et al. Testing the efficacy of RNA interference in Haemonchus contortus. Int J Parasitol. 2006;36(7):801-10. https://doi.org/10.1016/j.ijpara.2005.12.004.

132. Issa Z, Grant WN, Stasiuk S, Shoemaker CB. Development of methods for RNA interference in the sheep gastrointestinal parasite, Trichostrongylus colubriformis. Int J Parasitol. 2005;35(9): 935-40. https://doi.org/10.1016/j.ijpara.2005.06.001.

133. Hussein AS, Kichenin K, Selkirk ME. Suppression of secreted acetylcholinesterase expression in Nippostrongylus brasiliensis by RNA interference. Mol Biochem Parasitol. 2002;122(1):91-4. 
134. Lustigman S, Zhang J, Liu J, Oksov Y, Hashmi S. RNA interference targeting cathepsin $\mathrm{L}$ and Z-like cysteine proteases of Onchocerca volvulus confirmed their essential function during L3 molting. Mol Biochem Parasitol. 2004;138(2):165-70. https://doi.org/10.1016/j.molbiopara.2004.08.003.

135. Visser A, Geldhof P, de Maere V, Knox DP, Vercruysse J, Claerebout E. Efficacy and specificity of RNA interference in larval life-stages of Ostertagia ostertagi. Parasitology. 2006;133(Pt 6):777-83. https://doi.org/10.1017/ S0031182006001004.

136. Islam MK, Miyoshi T, Yamada M, Tsuji N. Pyrophosphatase of the roundworm Ascaris suum plays an essential role in the worm's molting and development. Infect Immun. 2005;73(4):1995-2004. https://doi.org/10.1128/IAI.73.4.1995-2004.2005.

137. Knox DP, Geldhof P, Visser A, Britton C. RNA interference in parasitic nematodes of animals: a reality check? Trends Parasitol. 2007;23(3):105-7. https://doi.org/10.1016/j.pt.2007.01.007.

138. Maule AG, McVeigh P, Dalzell JJ, Atkinson L, Mousley A, Marks NJ. An eye on RNAi in nematode parasites. Trends Parasitol. 2011;27(11):505-13. https://doi.org/10.1016/j.pt.2011.07.004.

139. Viney ME, Thompson FJ. Two hypotheses to explain why RNA interference does not work in animal parasitic nematodes. Int $\mathrm{J}$ Parasitol. 2008;38(1):43-7. https://doi.org/10.1016/j.ijpara.2007. 08.006 .

140. Zawadzki JL, Kotze AC, Fritz JA, Johnson NM, Hemsworth JE, Hines BM, et al. Silencing of essential genes by RNA interference in Haemonchus contortus. Parasitology. 2012;139(5):613-29. https://doi.org/10.1017/S0031182012000121.

141. Rosso MN, Jones JT, Abad P. RNAi and functional genomics in plant parasitic nematodes. Annu Rev Phytopathol. 2009;47:20732. https://doi.org/10.1146/annurev.phyto.112408.132605.

142. Dulovic A, Streit A. RNAi-mediated knockdown of daf-12 in the model parasitic nematode Strongyloides ratti. PLoS Pathog. 2019;15(3):e1007705. https://doi.org/10.1371/journal.ppat. 1007705 .

143. Castelletto ML, Massey HC Jr, Lok JB. Morphogenesis of Strongyloides stercoralis infective larvae requires the DAF-16 ortholog FKTF-1. PLoS Pathog. 2009;5(4):e1000370. https:// doi.org/10.1371/journal.ppat.1000370.

144. Lok JB. CRISPR/Cas9 mutagenesis and expression of dominant mutant transgenes as functional genomic approaches in parasitic nematodes. Front Genet. 2019. https://doi.org/10.3389/fgene. 2019.00656 .

145. Kramme S, Nissen N, Soblik H, Erttmann K, Tannich E, Fleischer $\mathrm{B}$, et al. Novel real-time PCR for the universal detection of Strongyloides species. J Med Microbiol. 2011;60(Pt 4):454-8. https://doi.org/10.1099/jmm.0.025338-0.

146. Lodh N, Caro R, Sofer S, Scott A, Krolewiecki A, Shiff C. Diagnosis of Strongyloides stercoralis: detection of parasitederived DNA in urine. Acta Trop. 2016;163:9-13. https://doi. org/10.1016/j.actatropica.2016.07.014.

147. Verweij JJ, Canales M, Polman K, Ziem J, Brienen EA, Polderman AM, et al. Molecular diagnosis of Strongyloides stercoralis in faecal samples using real-time PCR. Trans R Soc Trop Med Hyg. 2009;103(4):342-6. https://doi.org/10.1016/j. trstmh.2008.12.001.

148. Blaxter ML, De Ley P, Garey JR, Liu LX, Scheldeman P, Vierstraete A, et al. A molecular evolutionary framework for the phylum Nematoda. Nature. 1998;392(6671):71-5. https://doi.org/ $10.1038 / 32160$.

149. Dorris M, Blaxter M. The small subunit ribosomal RNA sequence of Strongyloides stercoralis. Int J Parasitol. 2000;30(8):939-41.

150. Hasegawa H, Hayashida S, Ikeda Y, Sato H. Hyper-variable regions in 18S rDNA of Strongyloides spp. as markers for speciesspecific diagnosis. Parasitol Res. 2009;104(4):869-74. https://doi. org/10.1007/s00436-008-1269-9.

151. National Research Council. Guide for the care and use of laboratory animals. Washington, D.C.: National Academic Press; 2011.

Publisher's Note Springer Nature remains neutral with regard to jurisdictional claims in published maps and institutional affiliations. 